\title{
Imperfect Information and Consumer Inflation Expectations: Evidence from Microdata
}

\author{
Lena Dräger* \\ Michael J. Lamla**
}

April 7, 2017

\begin{abstract}
This paper explores which factors trigger an adjustment in consumers' inflation expectations and looks at the implications regarding forecast errors. We find support for imperfect information models, as inflation volatility and news trigger an adjustment in expectations. Furthermore, we document that individual expectations become more accurate if they have been adjusted.
\end{abstract}

Keywords: Rational Inattention, updating inflation expectations, microdata, news.

JEL classification: D84, E31.

Word count: 11.962

*Johannes Gutenberg-University Mainz. Email: ldraeger@uni-mainz.de

**University of Essex and ETH Zurich, KOF Swiss Economic Institute. Email: mlamla@essex.ac.uk. The authors would like to thank the editor and two anonymous referees as well as Robert Anderson, Olivier Coibion, Damjan Pajfar, Ricardo Reis as well as seminar and conference participants at the 2014 ASSA meeting in Philadelphia, the University of Bonn, the University of Hamburg, the University of Essex, and the National Bank of Poland for helpful comments and suggestions. All remaining errors are our own. 


\section{Introduction}

Inflation expectations play a central role in modern macroeconomic models and are an important factor for economic policy. Despite their importance, we still know relatively little about how people form their expectations. Researchers have proposed a wide array of frameworks to model the expectations formation process. Contributions by Sims (2003), Mankiw and Reis (2002) or Woodford (2001) revived the interest in information rigidities and highlight their importance for the process of forming inflation expectations. ${ }^{1}$ Accounting for imperfect information allows to solve several empirical puzzles that did not match the predictions of the full-information rational expectations models, as shown in Ball et al. (2005). ${ }^{2}$

While recent approaches have used micro survey data of professional forecasters to identify the degree of information rigidities (Andrade and Le Bihan, 2013; An et al., 2016), so far there is only little evidence for consumers. The idea of this paper is thus to use the updating behavior regarding inflation expectations of individual consumers in order to provide evidence of imperfect information using a better identification based on micro survey data. We calculate the updating frequency over time and test which macroeconomic factors trigger an adjustment of inflation expectations. ${ }^{3}$ In doing so, we empirically test the relevance of theoretical imperfect information models, such as rational inattention as proposed by Sims (2003) or sticky information as introduced by Mankiw and Reis (2002). Furthermore, we explore if updating improves forecast accuracy of expectations.

For our analysis we make use of the rotating panel microstructure of the University of Michigan Survey of Consumers, where a fraction of individuals is re-interviewed after six months. This allows us to track individuals and their expectations with two observations over a period of six months. Hence, we can directly calculate the change in individual expectations and the share of individuals that have adjusted their expectations and, thus,

\footnotetext{
${ }^{1}$ Similarly, the literature on the importance of learning for the expectation formation process discusses how individuals use past data to learn about the true data generating process over time (Evans and Honkapohja, 2001; Malmendier and Nagel, 2016).

${ }^{2}$ For an overview see also Mankiw and Reis (2011).

${ }^{3}$ Note that we discussed the dataset and the calculation of the updating shares in Dräger and Lamla (2012). Consequently, in this paper we focus on whether we can explain the movements in the updating frequencies and explore the consequences for forecast accuracy.
} 
do not need to rely on identification coming only from the cross section or the aggregated series.

In Dräger and Lamla (2012) we have shown that there is a pronounced time variation in the updating frequency. This pronounced time-variation in the qualitative expectation updating share calls into question the assumption of a constant $\lambda$ in standard sticky information models and favors noisy information models or time-varying sticky information models. While this is interesting per se as it is useful for providing guidance in calibrating the updating probability in sticky information models, it does not tell us why we observe this time variation. At a micro level, both sticky information and rational inattention models posit that the optimal degree of attentiveness is a function of signals, such as the volatility of the forecast variable and news (Sims, 2003; Reis, 2006). In this paper, we thus test the evidence of imperfect information in consumers' inflation expectations and derive hypotheses from both rational inattention and sticky information models regarding agents' expectation updating behavior.

Our results provide evidence in favor of imperfect information, since we find that measures of the volatility of inflation raise attention and consequently trigger an updating of inflation expectations by consumers. In addition, we find support for news effects: If people have heard news on inflation, they are more likely to adjust their expectations.

Moreover, we explore whether adjusting expectations has beneficial implications for the accuracy of inflation expectations. Besides proving theories of rational attention it is extremely relevant to check whether adjusting expectations has improved the situation of individuals implying that they not only adjust expectations but improve the forecast and thereby allow for better economic action in response to this adjustment. Indeed, we can report that forecast accuracy increases if inflation expectations are adjusted.

To our knowledge, this is the first paper that uses the rotating panel dimension of the microdata in the University of Michigan Survey of Consumers to test for predictions from theories of expectation formation under imperfect information regarding consumers' inflation expectations. Nevertheless, there exist several approaches in the literature that test consumers' expectation formation for evidence of information frictions in aggregate data. For the US, Carroll (2003) finds support in aggregate survey data for the conjecture 
of Mankiw and Reis (2002) that consumers update their quantitative inflation expectations roughly once a year. For Europe, Döpke et al. (2008a) estimate that consumers update their inflation expectations once every 18 months. ${ }^{4}$ Mankiw et al. (2003) as well as Branch (2007) use aggregate survey data of consumers' inflation expectations to test for specific features of the sticky information model, while Lamla and Sarferaz (2012) document substantial time-variation in the inflation expectation updating behavior of German households.

Additionally, there exists evidence of information frictions in micro survey data for professional forecasters: Using microdata for inflation expectations of professional forecasters, Andrade and Le Bihan (2013) report evidence of information frictions as forecasters show staggered updating of expectations and persistent disagreement. An et al. (2016) use a similar measure to derive an aggregate inattention measure from professional forecasters' inattention to several variables and report substantial time-variation in inattention over the business cycle. Looking at the movements of forecast errors in relation to the variable being forecasted, Coibion and Gorodnichenko (2012, 2015) document pervasive and robust evidence consistent with information rigidities and derive a test for information frictions consistent under both sticky information and models of imperfect information as in Woodford (2001). Similarly, Dovern et al. (2015) use a related approach with both aggregate and individual survey data of professional forecasts in a large country panel. Our approach differs from these studies in that we focus on consumers' expectations. Specifically, we employ the rotating panel feature of the Michigan Survey for Consumers to identify updates in inflation expectations and derive hypotheses from limited information theories that we test in the regression analysis. We therefore focus on the determinants of the likelihood of an individual expectation update.

So far, only a few studies use the rotating panel dimension of the University of Michigan Survey of Consumers. Souleles (2004) employs the rotating panel to construct individual forecast errors, which are then subjected to rationality tests and evaluated with respect to their forecasting power regarding household expenditure. Anderson et al. (2010) analyze differences in the formation of consumers' inflation expectations and their forecast errors

\footnotetext{
${ }^{4}$ For evidence regarding the expectations updating by professional forecasters, see Döpke et al. (2008b).
} 
conditional on sociodemographic characteristics. Pfajfar and Santoro (2013) test the hypotheses of the epidemiology model proposed by Carroll (2003). Finally, Bachmann et al. (2015) test for a possible link between individual consumers' inflation expectations and their reported readiness to spend on large consumer goods.

The paper is structured as follows. We discuss models with imperfect information in section 2, where we derive our hypotheses for the empirical analysis. In section 3 we discuss the data set used in the analysis. Empirical results regarding the updating behavior of individual inflation expectations and their forecast errors are presented in section 4. Section 5 concludes.

\section{Theoretical Determinants of Imperfect Information}

In order to derive testable hypotheses for individuals' updating behavior, we present two simple models of inflation expectations under imperfect information. Following the seminal paper by Sims (2003), models of rational inattention assume that individuals are constrained in their capacity to acquire and process information and, hence, may not be able to form full information rational expectations. Some information is observed each period and individuals may choose where to allocate their limited attention, so that the updating of expectations becomes a function of signals. In a related class of models, the sticky information model by Mankiw and Reis (2002) assumes that agents underly a constant probability of being able to update their information set each period. Nevertheless, the optimal updating frequency at the micro level also depends on signals (Reis, 2006). Our test hypotheses derived from the models below account for aspects of both rational inattention and sticky information models. Hence, we test for the relevance of imperfect information models in general and do not aim at discriminating between different approaches of modeling imperfect information.

The structure of the first model presented here follows closely the example in Wiederholt (2010), who presents a model of price setting under rational inattention. Since individuals may update their expectations each period, the model can be written as a 
static problem, omitting time indices. Suppose that the full information rational forecast of inflation, $\pi^{e, *}$, is given by:

$$
\pi^{e, *}=\theta \Delta
$$

where $\Delta \sim N\left(0, \sigma_{\Delta}^{2}\right)$ is a combination of aggregate shocks driving inflation, which is assumed to be normally distributed with mean zero and variance $\sigma_{\Delta}^{2}$, and $\theta$ is a parameter. Individuals cannot fully observe $\pi^{e, *}$. However, if they choose to pay attention to inflation, they will receive an individual signal $s_{i}=\Delta+\varepsilon_{i}$, where the idiosyncratic noise $\varepsilon_{i}$ is independent from aggregate shocks $\Delta$ and is also assumed to be normally distributed as $\varepsilon \sim N\left(0, \sigma_{\varepsilon}^{2}\right)$, so that $s_{i}$ is multivariate normal. Note that the individual signals $s_{i}$ may be interpreted as active searching for information on the part of individuals. Thus, individuals' inflation forecast, $\pi_{i}^{e}$, can be stated as:

$$
\pi_{i}^{e}=E\left[\pi^{e, *} \mid s_{i}\right]
$$

Next, the amount of information conveyed in the signal is measured as a reduction in uncertainty. In line with information theory, uncertainty is measured by the entropy of a random variable. In our model with Gaussian shocks, entropy of a random variable $x \sim N\left(0, \sigma_{x}^{2}\right)$ is given by:

$$
H(x)=\frac{1}{2} \log _{2}\left(2 \pi e \sigma_{x}^{2}\right)
$$

Similarly, the conditional entropy of $x$ given the signal $s_{i}$ can be written as:

$$
H\left(x \mid s_{i}\right)=\frac{1}{2} \log _{2}\left(2 \pi e \sigma_{x \mid s_{i}}^{2}\right)
$$

where $\sigma_{x \mid s_{i}}^{2}$ is the conditional variance of $x$ given $s_{i}$. Hence, the amount of information on $x$ in $s_{i}$, called mutual information, is given by the change in entropies conditional on the observation of the signal:

$$
I\left(x ; s_{i}\right)=H(x)-H\left(x \mid s_{i}\right)
$$


Inflation in the model is driven by aggregate shocks $\Delta$, so that we replace $x$ with $\Delta$ to get the mutual information in the signals $s_{i}$ on inflation shocks $\Delta$. When forecasting inflation under less than full information, individuals thus incur a loss, since an inaccurate inflation forecast leads for instance to suboptimal pricing decisions or wage negotiations. Hence, individuals aim at minimizing these losses subject to their information processing constraint. We assume that individuals can choose both the amount of attention $\kappa$, paid to inflation at a cost $\mu$, and the signals obtained. Additionally, we assume that the marginal cost $\mu$ of an additional unit of attention devoted to inflation is a negative function of public news on inflation, $N$, as perceived by the individual: $\mu(N)$ with $\mu^{\prime}(N)<0 .{ }^{5}$ We argue that this effect reflects passive learning about inflation developments, for instance via the exposure to media news, which then reduces the individual marginal cost of actively searching for information on inflation. Hence, the problem of optimal inattention can be stated as follows:

$$
\min _{\sigma_{\Delta \mid s_{i}}^{2} \kappa \geq 0} E_{\Delta, s_{i}}\left[\left(\pi_{i}^{e}-\pi^{e, *}\right)^{2}\right]+\mu(N) \kappa
$$

subject to equations (1) and (2), $s_{i}=\Delta+\varepsilon_{i}$ and the information constraint

$$
\frac{1}{2} \log _{2}\left(2 \pi e \sigma_{\Delta}^{2}\right)-\frac{1}{2} \log _{2}\left(2 \pi e \sigma_{\Delta \mid s_{i}}^{2}\right) \leq \kappa
$$

Agents minimize (6) over the joint distribution of the true inflation state and the signal, where the joint distribution is chosen to be Gaussian due to the assumption of Gaussian states. $^{6}$ This gives an expression for optimal attention towards inflation:

$$
\kappa^{*}=\left\{\begin{array}{cl}
\frac{1}{2} \log _{2}\left(\frac{2 \ln (2) \theta^{2} \sigma_{\Delta}^{2}}{\mu(N)}\right) & \text { if } \frac{2 \ln (2) \theta^{2} \sigma_{\Delta}^{2}}{\mu(N)} \geq 1 \\
0 & \text { otherwise }
\end{array}\right.
$$

\footnotetext{
${ }^{5}$ The cost of attention $\mu$ may also vary across demographic characteristics and could, for instance, be lower for individuals with a higher economic and financial literacy. Here, we make the simplifying assumption that $\mu$ is not heterogeneous across agents, but in the regression analysis control for demographic factors.

${ }^{6}$ The full derivation of the optimality problem and the optimal degree of attention is given in the appendix.
} 
where the fraction $\left(2 \ln (2) \theta^{2} \sigma_{\Delta}^{2}\right) / \mu(N)$ gives the marginal benefit of paying attention to inflation. From equation (8), we can thus state two hypotheses regarding attention towards inflation: ${ }^{7}$

H1: Under rational inattention, updates of inflation expectations, i.e. attention towards inflation, should be a positive function of the variance of inflation forecasts under full information $\theta^{2} \sigma_{\Delta}^{2}$, which is driven by the variance of aggregate shocks on inflation.

H2: Under rational inattention, attention towards inflation should be a positive function of news $N$ regarding inflation perceived by the individual, since these reduce the marginal cost $\mu$ of devoting attention to inflation.

A related approach to implications of imperfect information can be found in Dräger (2016) in a model which bridges models of rational inattention and of sticky information. In line with the literature on heterogeneous expectations, individuals in the model in Dräger (2016) may choose between two forecasts of inflation, where one forecast is formed under full information $\left(E^{F I}\right)$, while the second forecast is formed with outdated (sticky) information $\left(E^{S I}\right)$. The aggregate expectations index for inflation expectations is then given by:

$$
\widetilde{E}_{t}(\pi) \equiv \lambda_{t}^{\pi} E_{t}^{F I}(\pi)+\left(1-\lambda_{t}^{\pi}\right) E_{t}^{S I}(\pi)=\lambda_{t}^{\pi} E_{t}(\pi)+\left(1-\lambda_{t}^{\pi}\right) \bar{\lambda} \sum_{j=0}^{\infty}(1-\bar{\lambda})^{j} E_{t-1-j}(\pi),
$$

where $\lambda_{t}^{\pi}$ is the endogenous and time-varying probability of choosing the full information forecast of inflation. The model thus derives a version of a sticky information model. Moreover, the model also incorporates aspects of rational inattention, since attention as captured by $\lambda_{t}^{\pi}$ may change every period. Individuals are assumed to base their decision for a forecast on its forecast performance, measured by the respective squared forecast

\footnotetext{
${ }^{7}$ Note that Reis (2006) derives at a similar conclusion regarding the determinants of consumers' optimal degree of inattentiveness in a model with sticky information. However, in contrast to models of rational inattention, the concept of sticky information assumes that forecasts are only updated within fixed intervals, so that the model in Reis (2006) yields in fact the optimal inattentiveness interval.
} 
errors. Additionally, full information can only be obtained at a fixed $\operatorname{cost} C^{F I}$, which has to be paid each period. Forecast attractiveness is thus given by the expressions:

$$
\begin{gathered}
V_{t}^{F I}=\left(\pi_{t-1}-E_{t-2} \pi_{t}\right)^{2}+C^{F I} \\
V_{t}^{S I}=\left(\pi_{t-1}-\bar{\lambda} \sum_{j=0}^{\infty}(1-\bar{\lambda})^{j} E_{t-j-3} \pi_{t}\right)^{2}
\end{gathered}
$$

The probability of choosing the full information forecast, given by each forecast's attractiveness from equations (10) and (11) is then modeled as a choice of two discrete alternatives under rational inattention. This implies that although individuals have some information on the predictors' accuracy, there remains some uncertainty regarding the optimal forecast or the true values in $V=\left(V^{F I}, V^{S I}\right)$. As shown in Matějka and McKay (2011), the probability of forecasting inflation with full information is in this case given by a multinominal logit model: ${ }^{8}$

$$
\lambda_{t}^{\pi}=\frac{\exp \left(V_{t}^{F I} / \mu\right)}{\exp \left(V_{t}^{F I} / \mu\right)+\exp \left(V_{t}^{S I} / \mu\right)},
$$

where $\mu$ is the cost of a unit of information derived above. From this model, we can thus state the third hypothesis regarding attention towards inflation:

H3: Under imperfect information and with a choice between costly new information or costless outdated information, attention towards inflation should increase with higher past forecast errors regarding inflation. ${ }^{9}$

All three hypotheses H1-H3 thus formulate testable hypotheses for evidence of imperfect information in expectation formation and will be brought to the data in the empirical analysis of consumers' inflation expectations below.

\footnotetext{
${ }^{8}$ Detailed derivations are given in Matějka and McKay (2011).

${ }^{9}$ Note that although they are derived from different models, hypotheses H1 and H3 are related in the sense that under imperfect information an increase in the variance of inflation is likely to also increase the forecast error, since expectations do not comove perfectly with the actual data.
} 


\section{The Data}

We analyze microdata from the University of Michigan Survey of Consumers, which is available for the sample period January 1978 to November 2011. Since October 1987, each month a sample of about 500 households is interviewed, where the sample is chosen to statistically represent households in the US, excluding Alaska and Hawaii. ${ }^{10}$ Sample sizes before $1987 \mathrm{~m} 10$ were about $600-1400$ interviews per month from 1978m1-1980m2, and about 600-700 interviews per month from 1980m3-1987m9. ${ }^{11}$

For the analysis of the dynamics of individuals' inflation expectations, we exploit the fact that the Michigan Survey of Consumers includes a rotating panel: Each month, a randomly determined sub-sample of households is chosen to be re-interviewed six months after the first interview. The complete cross-section each month includes about $40 \%$ of individuals that are interviewed for the second time. Via the rotating panel structure of the survey, we are thus able to identify changes in expectations on an individual consumer level. In this paper, we use cross-sections from October 1987 onwards. This allows us to exclude any effects from the downward trend in inflation during the disinflation period and the simultaneous monetary policy shocks on our results, and ensures a homogeneous sample size of about 400 individuals within the rotating panel each month. ${ }^{12}$

In order to identify individual changes in inflation expectations at a micro level, we follow Souleles (2004) and Pfajfar and Santoro (2013) and restrict our sample to households where the same person answered both interviews. Additionally, we control for extreme values for inflation expectations by truncating our sample at the upper and lower $2.5 \%$ of the distribution of both short- and long-run quantitative inflation expectations.

For the evaluation of changes in individuals' inflation expectations, we are able to exploit the fact that, in addition to a qualitative question asking about expectations regarding "prices in general", the Michigan Survey includes questions asking for a quantitative estimate of expected inflation. Moreover, the survey allows to distinguish between

\footnotetext{
${ }^{10}$ Interviews generally take place in the first half of each month.

${ }^{11}$ For further details on the University of Michigan Survey of Consumers, see http://www.sca.isr.umich.edu.

${ }^{12}$ For a discussion on the selection of the sample using the MSC see Carvalho and Nechio (2014) and Dräger et al. (2016). We check for robustness of our results with respect to the sample period and present estimations for our main results with the full sample period in section 4.4.
} 
individuals' expectations regarding inflation during the next year and expectations at a longer horizon of five to ten years. The precise questions of the survey read:

A12. "During the next 12 months, do you think that prices in general will go up, or go down, or stay where they are now?"

\section{GO UP 3. STAY THE SAME 5. GO DOWN 8. DON'T KNOW}

A12b. "By about what percent do you expect prices to go (up/down) on the average, during the next 12 months?"

A13. "What about the outlook for prices over the next 5 to 10 years? Do you think prices will be higher, about the same, or lower, 5 to 10 years from now?"

\section{HIGHER 3. STAY THE SAME 5. LOWER 8. DON'T KNOW}

A13b. $\quad$ "By about what percent per year do you expect prices to go (up/down) on the average, during the next 5 to 10 years?"

As we are interested in evaluating the role of information frictions for the formation of inflation expectations, we employ the question in the Michigan Survey of Consumers asking for news on the economy heard by the respondent as a measure of perceived news regarding inflation. The wording of the question is as follows:

A6. "During the last few months, have you heard of any favorable or unfavorable changes in business conditions?"

1. YES 2. NO

If the question is answered with "yes", an open question with two possible answers follows:

A6a. "What did you hear? (Have you heard of any other favorable or unfavorable changes in business conditions?)"

The answers are coded into categories by the Michigan Survey of Consumers. For our purposes, we construct a dummy variable "newsheard" if the consumer reports having 
heard any news on business conditions in general, and a dummy "newsprices" which takes on the value of 1 if the respondent reported news heard on either "falling prices/deflation", "high prices/inflation", "higher prices/inflation is good" or "lower, stable prices/less inflation" and zero otherwise. Additionally, we distinguish between news heard about high and low inflation or prices with the dummy variables "newsprices_high" and "newsprices_low". In order to be able to distinguish between favorable or unfavorable news regarding inflation, we further construct the dummy variables "newsprices_bad" and "newsprices_good". We code news on "higher prices/inflation is good" and on "lower, stable prices/less inflation" as favorably perceived by the respondent, while the other two categories are coded as unfavorable news.

Table 1: Summary Statistics of the Monthly Shares of Consumers Reporting News Heard

\begin{tabular}{l|ccccc}
\hline \multicolumn{1}{c|}{ Variable } & Obs & Mean & SD & Min & Max \\
\hline Share newsheard & 58,552 & 0.60 & 0.10 & 0.39 & 0.87 \\
Share newsprices & 58,552 & 0.05 & 0.06 & 0.00 & 0.36 \\
Share newsprices_high & 58,552 & 0.05 & 0.06 & 0.00 & 0.36 \\
Share newsprices_low & 58,552 & 0.01 & 0.01 & 0.00 & 0.11 \\
Share newsprices_bad & 58,552 & 0.04 & 0.06 & 0.00 & 0.36 \\
Share newsprices_good & 58,552 & 0.01 & 0.01 & 0.00 & 0.11
\end{tabular}

Notes: Results for the sample period from 1987m10-2011m11. Obs denotes the sample size, $S D$ is the standard deviation while Min and Max represent the minimum and maximum values.

From the summary statistics in Table 1 we observe that on average about $60 \%$ of the people surveyed report having heard news on business conditions in general, while only $5 \%$ heard news on price developments. These are mainly news about rising prices, which are mostly perceived as bad news. While this seems a rather small number, one should note that survey participants can only state two news items and that news on prices competes along other important economic and political dimensions like employment, taxes, fiscal debt, etc. In addition, the price movements in our sample have been quite moderate and inflation fears are not expected to have dominated the economic debate throughout. Nevertheless, we also note substantial time variation in all shares reporting news, with maximum shares of up to one third observing news on inflation. As shown in Figure A.1 in the Appendix, consumers generally observe more news during recessionary periods. This 
is also the case with news on price changes, where we additionally observe an increased number of reported news from the mid-2000s to the end of the Great Recession.

Furthermore, we employ a number of sociodemographic control variables from the Michigan Survey of Consumers in the following analyses, such as age and sex of the respondent as well as income quartiles and a categorical variable measuring education of the respondent in six categories. These are defined as follows: Educ1 - "Grade 0-8, no high school diploma", Educ2 - "Grade 9-12, no high school diploma", Educ3 - "Grade 0-12, with high school diploma", Educ4 - "4 yrs. of college, no degree", Educ5 - "3 yrs. of college, with degree" and Educ6 - "4 yrs. of college, with degree".

In addition to the microdata from the Michigan Survey of Consumers, we employ monthly data on actual U.S. CPI inflation from the FRED database of the St. Louis FED. Monthly data for Treasury-bill constant maturity secondary market rates is also extracted from the FRED database. We further use quarterly data of inflation expectations regarding U.S. inflation from the Survey of Professional Forecasters (SPF), which is available from 1981q3 onwards for one-year-ahead inflation forecasts, and from 1991q4 onwards for ten-years-ahead inflation forecasts. Finally, we account for the attention of the media to topics related to U.S. inflation with the number of articles published on U.S. inflation in the New York Times. This measure of external information is obtained from the media research institute MediaTenor and is available on a monthly basis from 1998m1 to $2011 \mathrm{~m} 5 .^{13}$

\section{Results}

\subsection{The Individual Updating Frequency of Inflation Expectations}

As a first step, we calculate the share of individuals in each monthly cross-section that adjusted their expectations, denoted as "updating share". ${ }^{14}$ In line with the literature, we interpret the updating share as the share of individuals which updated their information, and, hence, also their expectations. However, it should be noted that in theory it might be

\footnotetext{
${ }^{13}$ This data is coded by humans following the standards of media content analysis. Unfortunately, the dataset starts only in $1998 \mathrm{~m} 1$ and an extension further into the past is outside the scope of this paper.

${ }^{14}$ The analysis in this subsection builds on Dräger and Lamla (2012).
} 
possible to update information on inflation and nevertheless keep expectations constant on the basis of new information. While we cannot verify this possibility, we note that in this case the updating share represents the lower bound of the monthly number of individuals which updated their information regarding inflation. Due to the nature of the survey, a further caveat applies: The Michigan Survey asks for forecasts for a fixed horizon of 12 months ahead, instead of forecasts with a fixed target date, say December of that year. Hence, 12-months-ahead expectations after six months have an overlapping forecasting horizon of only six months with the previous 12-months-ahead expectations, so that changes in expectations may occur even if the consumer remained inattentive. This could lead to overestimation of the updating frequency.

The updating share is calculated for both short- and long-run inflation expectations captured by both the qualitative and the quantitative answers. Summary statistics are given in Table 2.

Table 2: Summary Statistics of the Monthly Updating Shares for Inflation Expectations

\begin{tabular}{l|ccccc}
\hline \multicolumn{1}{c|}{ Variable } & Obs & Mean & SD & Min & Max \\
\hline Short-run expectations, 1 year & 289 & 0.74 & 0.06 & 0.60 & 0.87 \\
Short-run expectations, 1 year, qualitative answer & 289 & 0.38 & 0.09 & 0.16 & 0.67 \\
Long-run expectations, 5-10 years & 255 & 0.72 & 0.06 & 0.57 & 0.86 \\
Long-run expectations, 5-10 years, qualitative answer & 255 & 0.17 & 0.05 & 0.03 & 0.34 \\
\hline
\end{tabular}

Notes: Results for the sample period from 1987m10-2011m11. Obs denotes the sample size, $S D$ is the standard deviation while Min and Max represent the minimum and maximum values.

According to our calculations, individuals in the Michigan survey on average update their one-year-ahead inflation expectations based on the quantitative question every 8 months and every 16 months based on the qualitative question. ${ }^{15}$ Regarding long-run inflation expectations, the updating frequencies vary between 8 and 36 months based on the quantitative and the qualitative question, respectively. Overall, we find higher updating frequencies using the answers to the quantitative question as reported in the

\footnotetext{
${ }^{15} \mathrm{As}$ is standard in the literature, the average updating frequency is derived from the updating shares by assuming that all consumers have the same likelihood of an expectations adjustment. Thereby, an updating share of, e.g., 0.74 over six months is equivalent to a share of 0.123 over one month. The monthly updating frequency is then given by the inverse, which gives roughly 8 months.
} 
literature from aggregate data. ${ }^{16}$ Using the population mean of quantitative inflation expectations from U.S. surveys, Carroll (2003) estimates an updating share of roughly 0.25 over a quarter, corresponding to a value of 0.5 over six months. This implies that expectations are updated once within a year. For Europe, using qualitative survey data, Döpke et al. (2008a) report a somewhat lower updating frequency than that in the U.S.: A typical household updates its inflation expectations roughly once in eighteen months. One possible explanation for our result of a higher updating frequency at the micro level may be related to the aggregation phenomenon. The effect that aggregation of individual data series reduces the variability of the underlying microdata and increases its persistence is a known result, e.g. from movements in price indices (Altissimo et al., 2007). Another explanation for the difference in updating frequencies might come from the fact that updating frequencies in aggregate data cannot simply be calculated as in our microdata, but must be estimated. The studies in Carroll (2003) and Döpke et al. (2008a) estimate an epidemiology model, where consumers are assumed to update their inflation expectations towards professionals' forecast. By contrast, our measure directly calculates changes in individual expectations without referring to any theoretical model.

Notably, the difference in the updating frequency between the qualitative and quantitative answers is quite remarkable. Given the way the questions are phrased, this suggests that individuals fine-tune their quantitative expectations very regularly (even though the Michigan Survey reports only full integer expectations), but update their qualitative expectations much less frequently. In line with central banks' definition of price stability as inflation in the range of $2 \%$, consumers who expect low inflation rates might answer "prices stay the same" and only move into the "prices increase" category once they expect higher inflation rates, and vice versa for prices expected to be "lower". An update in an individual's qualitative inflation expectations should thus be viewed as a larger change in expected inflation. Indeed, consumers might update their information set, but nevertheless decide not to change their qualitative assessment of expected inflation. This implies

\footnotetext{
${ }^{16}$ The Michigan Survey imposes that quantitative inflation expectations be stated as full numbers, excluding decimals. Therefore, an update of quantitative inflation expectations implies a change of at least one percentage point. Hence, we capture as "updating" already a meaningful deviation from the preceding forecast. In order to test whether more substantial changes have different effects, we also analyze updating frequencies with expectation changes larger than 1 or 5 percentage points. Results are presented in the robustness section 4.4.
} 
that qualitative inflation expectation updates should co-move with substantial adjustments in the quantitative assessment. Indeed, as shown in Figure A.2 in the appendix, updating shares calculated from quantitative inflation expectations with absolute changes larger than $1 \%$ or $5 \%$ are closer to the updating share of qualitative expectations. Alternatively, the high updating share reported from the quantitative question might also be a hint to macroeconomic illiteracy or memory loss (Blanchflower and Kelly, 2008): Some individuals might not have changed their view on inflation, but fail to recall the exact number reported six months ago. This might introduce some measurement error in the rather high updating share for quantitative expectations.

To test the hypothesis of fine-tuning, we check whether the mean change in quantitative expectations is smaller if there is no change in the qualitative assessment. For this purpose we employ comparison of mean tests with different variances. Conducting those tests, we find support for the hypothesis that quantitative changes are indeed significantly smaller if the qualitative response did not change. ${ }^{17}$ This implies that the high updating frequency identified from the quantitative answer represents mainly only very gradual adjustments, where larger adjustments occur when qualitative expectations are adjusted as well. To test the hypothesis with regard to macroeconomic illiteracy, we check whether updating of inflation expectations improves the forecast accuracy. If updating significantly alters forecast errors, this should hint to a sufficient degree of macroeconomic literacy and hence imply that the updating we identify is indeed something very meaningful. The results of this analysis are presented in the upcoming section.

Coming back to the different results presented in the literature for the updating propensity of U.S. and European consumers, our study allows for an insight that challenges this result. In fact, our data suggests that this difference between U.S. and European consumers might be driven by the type of survey data available: Qualitative vs. quantitative data. In the above paragraph, the results of Döpke et al. (2008a) indicate that European consumers are more sluggish in adjusting their expectations than US consumers. This result is based on qualitative data, while the results for the U.S. are based on quantitative

\footnotetext{
${ }^{17}$ Test statistics equality of means t-test with unequal variances and with $\mathrm{H} 0$ : difference of means $=0$. One-year expectations: $t$-value $=-32.81$, Satterthwaite's degrees of freedom $=16808$, $\mathrm{p}$-value $=0.000$; test 5 -10 years expectations: $t$-value $=-19.79$, Satterthwaite's degrees of freedom $=3692.68, \mathrm{p}$-value $=0.000$
} 
data. If we now consider that our results for the U.S. show that qualitative expectations are adjusted less frequently than quantitative expectations, the reported difference in those studies comparing European and U.S. consumers may be only driven by the fact that different types of survey data were used and consequently may imply that the US and Europe have very similar updating frequencies.

Long-run expectations are adjusted less often than short-run expectations at least in the case of qualitative expectations, and hence seem more firmly anchored on average. Long-run expectations should not be affected much by business cycle effects, but rather be related to fundamental factors. Such fundamentals might include the long-run stance of monetary policy, for instance with respect to an inflation target. Notably, the high updating share for long-run quantitative inflation expectations may again be affected by fine-tuning or macroeconomic illiteracy.

Our results may be useful to the calibration of structural parameters in sticky information models. In their quarterly model, Mankiw and Reis (2002) assume a constant expectations updating probability of $\lambda=0.25$, which means that consumers update their inflation expectations on average once a year. Our results then point out important implications for the calibration of $\lambda$ in sticky information models: First of all, it is important to distinguish between the updating of quantitative and qualitative expectations (i.e., fine-tuning vs substantial adjustments), since the more frequent updates in quantitative inflation expectations would imply a value of $\lambda=0.37$, while the more substantial adjustments in qualitative expectations give $\lambda=0.19$. Second, if expectation updates in sticky information models should capture a more substantial adjustment of inflation expectations, $\lambda$ should be calibrated at the lower value around $\lambda=0.19$.

Next, we plot the share of households that update their inflation expectations over time together with a smoothing polynomial trend, shown in Figure 1. Several approaches in the literature report evidence that updating shares regarding inflation expectations in the population may vary substantially over time. Coibion and Gorodnichenko (2015) show that the information rigidity changes over the business cycle and Lamla and Sarferaz (2012) relate the variation of the updating speed for expectations of German consumers to uncertainty and news effects. Finding time-varying updating frequencies would contradict 
Figure 1: Updating Shares for Inflation Expectations

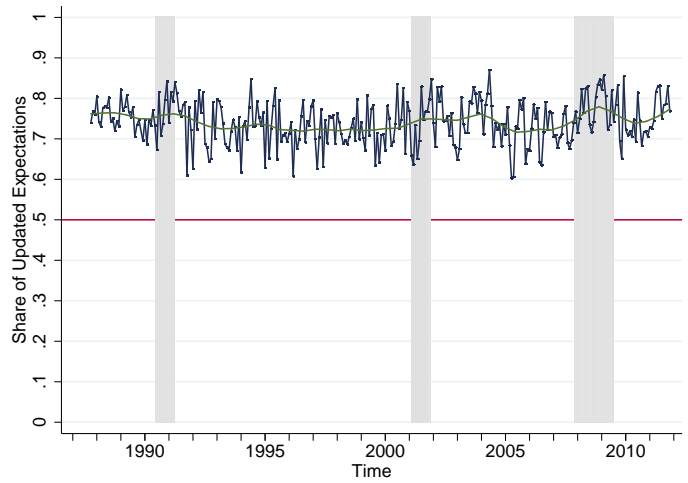

(a) Short-run expectations, 1 year

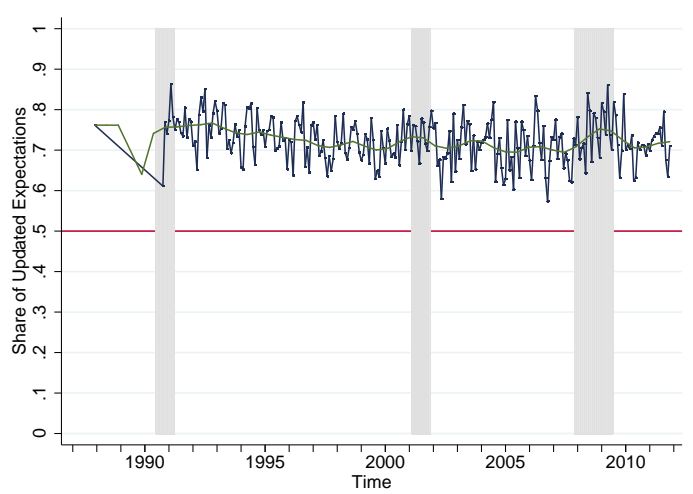

(c) Long-run expectations, 5-10 years

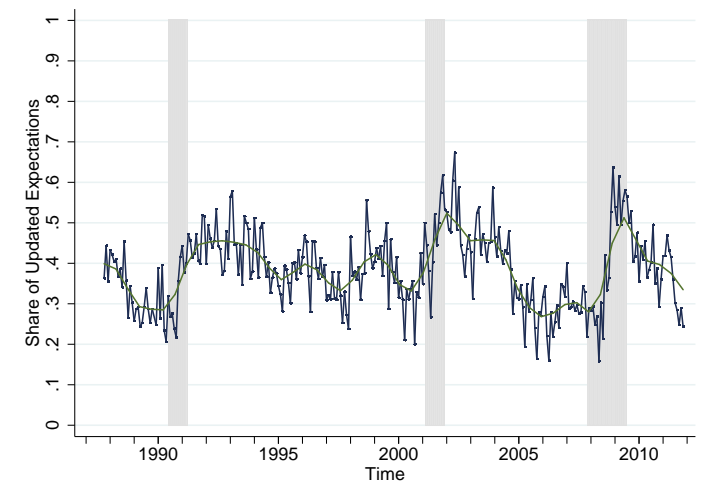

(b) Short-run expectations, 1 year, qualitative answer

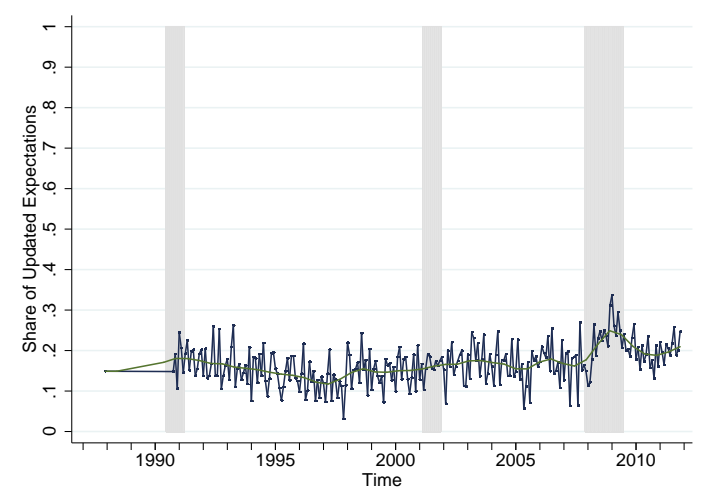

(d) Long-run expectations, 5-10 years, qualitative answer

Notes: The graphs show the share of individual consumers that change their inflation expectations within six months together with a smoothing polynomial trend. Shaded areas are recession phases as identified by the NBER. The share is calculated by taking all individuals that adjusted their expectations during the last six months and dividing them by the overall number of individuals that have been re-interviewed.

the assumptions in sticky information models, where the aggregate updating share of individuals is assumed to stay constant over time. By contrast, rational inattention models assume that agents may update their expectations every period.

Looking at the changes in qualitative one-year-ahead inflation expectations, we can observe substantial variation in the updating share, which fluctuates between about $20 \%$ and $60 \%$. Interestingly, we see relatively strong surges during recessionary periods. Especially from 2008 onwards, the share of individuals that updated their inflation expectations rose substantially. The cyclical pattern is also present in the updating share of quantitative short-run expectations, albeit less pronounced. Hence, our results imply that aggregate sticky information models miss some properties of the expectation formation 
process. Aternatively, our results may give empirical motivation to other models, e.g., hybrid models with time-varying sticky information as in Dräger (2016).

Regarding the updating shares of long-run inflation expectations, we find significantly less time-variation compared to one-year-ahead inflation expectations. Fundamentals and the monetary policy stance should not change often and hence a rather constant updating share has to be expected. Unfortunately, the question on long-run inflation expectations was not included in every monthly survey before October 1990, leading to missing values in the time series of the updating shares. For the following regression analysis, we thus restrict the sample period for individual long-run inflation expectations to a start in October 1990.

Furthermore, we are interested in the determinants of updating, which we will evaluate in more detail in the regression analysis of the following section. One important source might be news observed by the consumer. In Table 3 we conduct a quick inspection on whether expectations on inflation move in a sensible way with respect to news heard on inflation. Indeed, we can confirm that consumers adjust their expectations as would be expected: If people hear news on rising prices or inflation, they will increase their quantitative inflation expectations and if they hear news on falling inflation, they will adjust their inflation expectations downwards. These changes are significant at least at the $5 \%$ level. Additionally, we observe that the absolute forecast error of people that hear news on higher inflation is much higher than that of people hearing news of lower inflation (see Table 12 in section 4.3).

Table 3: Response of Quantitative Inflation Expectations to News on Prices

\begin{tabular}{l|cccc}
\hline \multicolumn{1}{c|}{ Variable } & Mean & SD & Obs & T-Test \\
\hline $\begin{array}{l}\text { News heard on high prices/inflation } \\
\text { Change in short-run quantitative expectations }\end{array}$ & 0.589 & 6.229 & 926 & $2.875^{* * *}$ \\
$\begin{array}{l}\text { News heard low prices/inflation } \\
\text { Change in short-run quantitative expectations }\end{array}$ & -1.198 & 6.506 & 177 & $-2.449^{* *}$ \\
\hline
\end{tabular}

Notes: The table shows changes in individual quantitative short-run inflation expectations in the case of an update, conditional on news observed by the consumer. Results are for the sample period from 1987m10-2011m11. SD is the standard deviation and $O b s$ denotes the sample size. The t-statistic gives the result of a test against the null hypothesis that the change in expectations is equal to zero. ${ }^{* * *},{ }^{* *}$ and ${ }^{*}$ denote significance at the $1 \%, 5 \%$ and $10 \%$ level, respectively. 


\subsection{Explaining Adjustments in Inflation Expectations}

In this section, we link the updating behavior regarding inflation expectations to possible determinants derived from the theories of imperfect information discussed in section 2 . Specifically, we estimate pooled cross-section probit models for the propensity to update both individual quantitative and qualitative short- and long-run inflation expectations in the second interview, including aggregate regressors derived from the theoretical models as well as demographic factors.

From the simple model of rational inattention regarding inflation derived in section 2, we get our first hypothesis H1, stating that attentiveness towards inflation should be affected by the variance of inflation forecasts under full information, i.e. the variance of actual inflation. This result is also presented in Maćkowiak and Wiederholt (2009) in a rational inattention model of price setting and in Reis (2006) in a sticky information model. In order to test for H1, we thus include both the variability of actual inflation and of professional forecasters' inflation outlook from the Survey of Professional Forecasters as determinants for the probability of an update of inflation expectations. We argue that the latter may be regarded as the best available forecast and, thus, as a proxy for the full information forecast even though professional forecasters may also potentially suffer from information rigidities. Actual inflation volatility is calculated as the sum of squared monthly changes of inflation from $t-2$ to $t-8$, while the volatility of professionals' forecasts comes from squared changes in the last two quarters. Information on both measures is thus available to all consumers interviewed in month $t$. According to $\mathrm{H} 1$, if the variability of either actual inflation or professional forecasts increases, people should pay more attention to inflation and, thus, have an increased probability to update their expectations. Additionally, we test for an effect of the volatility of mean forecasts from month $t-2$ to $t-8$ over all consumers.

Next, we attempt to evaluate hypothesis $\mathrm{H} 2$ from the rational inattention model by testing for the effect of news on individuals' updating behavior. Hypothesis H2 states that attention towards inflation should be a positive function of news regarding inflation, as these should lower the marginal cost of attention and, thus, increase the probability of an update. This is in line for instance with arguments in Lamla and Sarferaz (2012). 
We account for news effects by including the change in the number of news on inflation in the media over the last six months and the individual change between interviews in the variable stating whether the individual observed any news on business conditions in general and on inflation in particular. We thus disentangle the sender and receiver perspective regarding the news. Additionally, we also account for possible asymmetries, e.g. that news heard on high inflation might be more likely to trigger an adjustment of expectations compared to news on low or falling inflation.

Finally, we test for evidence regarding hypothesis H3, which was derived from the model in Dräger (2016). Under H3, the probability of updating inflation expectations should be positively affected by an increase in individuals' own past forecast errors, since the predictor formed with outdated information becomes less attractive, the higher its forecast error. We thus include the absolute individual forecast error from the first interview as an explanatory variable for the propensity to update expectations in the second interview. Notably, as we have only a six-months lag between both interviews, the forecast error from six months ago has not been fully realized yet. Therefore, we calculate annualized inflation during the six months between the interviews and a hypothetical absolute forecast error assuming that individuals forecast this realized annualized inflation instead of 12-months ahead inflation in the first interview. This measure is used to instrument the individual absolute forecast error reported in the first interview.

Tables 4-10 comprise the estimation results for the probability of updating inflation expectations. Tables 4-7 show models including different measures of inflation volatility as well as individual absolute forecast errors as determinants for the updating of both short- and long-run quantitative and qualitative inflation expectations, where Tables 6-7 test for non-linear effects of inflation volatility. In a second set of tables, i.e. Tables 8 and 9, we test for the effects of different news variables. Finally, Table 10 tests for asymmetric effects between consumers that increase or decrease their inflation forecast in the second interview. All tables report marginal effects evaluated with the remaining variables being held at their means, with standard errors clustered at the year level and all models additionally include demographic controls such as age and sex of respondent as well as education and income groups. Overall, we find that the suggested explanatory 
variables can explain more of the short-run updating behavior than the long-run updating behavior. This is certainly in line with our expectations. Long-run expectations should be more related to fundamental factors that vary only little over time and are not sufficiently captured by our set of determinants. We focus here on the results regarding the updating of short-run inflation expectations and show regressions with long-run expectations in the Appendix.

Regarding the updating of short-run inflation expectations, we find that an increase in the volatility of professionals' inflation forecasts significantly increases the probability of an update of both individual quantitative and qualitative inflation expectations. Generally, we thus find evidence in favor of $\mathrm{H} 1$ and, hence, in favor of imperfect information.

The existence of imperfect information can further imply a non-linear effect of the forecasted variable's variance (conditional on other factors) on the updating of expectations, as shown in equation (8). Individuals pay attention if a certain threshold is reached. This might affect our results in the linear additive framework we are estimating. To account for the possible non-linearity in the simplest way, we add squared terms of our inflation variance measures. If the threshold is non-binding at low levels, but binding at higher levels of the observed variance, we should observe a significant squared term. By contrast, if the threshold already binds at very low levels of the variance, only the level effect should be significant. Results are presented in Tables 6 and 7 and depicted in Figure 2. Accounting for a non-linear impact of the inflation variance has no effect on our news variable as it stays significant for quantitative expectations and remains irrelevant for qualitative expectations. Looking at our measures of inflation variance, we observe that the squared term of the CPI variance is highly significant for qualitative inflation expectations, indicating that more people update their expectations once the CPI variance reaches a certain threshold. For quantitative expectations we find no statistically significant evidence of non-linearities. Figure 2 depicts marginal effects on the likelihood of an expectations update at different values of the CPI variance. The left panel shows the marginal effect for quantitative expectations, and the right figure depicts the same effect for qualitative expectations. While both graphs suggest an increasing effect of higher levels of inflation volatility on the likelihood of an update, this is only significant for qualitative expecta- 
tions. Overall, these results nicely re-enforce the notion of rational inattention. When we analyze the variance of inflation expectations of professional forecasters, it appears that the threshold is rather low as the squared term is insignificant. The effect of the variance of inflation expectations of consumers remains insignificant.

With respect to the hypothesis H3, we find that own past forecast errors from the first interview positively affect the probability of an expectations update in the second interview in all models in Tables 4-5. In line with H3, this suggests that consumers' own forecast accuracy may be used as a signal regarding the benefit of an information update.

Evaluating the news measures, we can report that news affect the propensity to update quantitative short-run inflation expectations only. More specifically, in the case of quantitative expectations, there is a significant impact of a change in perceived news on business conditions in general, as well as on prices changes. Our result of no significant effect of news on long-run inflation expectations can be interpreted as a high degree of anchoring of long-run expectations. Regarding the short-run, and knowing that a qualitative change implies a stronger movement in quantitative expectations, we can interpret the results to imply that news affect mainly smaller adjustments in inflation expectations, while larger adjustment can be better explained by our volatility measures and the realized forecast error. Overall, we thus find some tentative evidence in favor of H2. ${ }^{18}$

Finally, we test whether our results for H1-H3 depend on the direction of inflation expectation updates. We define a new dummy that takes on the value of 1 if the consumer reports an increase in short-run quantitative inflation expectations at the second interview, and a value of 0 if a decrease in expectations is reported. No change in expectations is coded as a missing value. The results in Table 10 show the marginal effects for the likelihood of reporting an increase in expected inflation. We observe that consumers are more likely to increase their inflation expectations, if they observe news on price changes. Since news observed by consumers are mostly news about price increases, we would expect that these news induce consumers to increase, rather than decrease, their inflation

\footnotetext{
${ }^{18}$ Overall, the suggested models can explain little of the overall variation as measured by the pseudo $R^{2}$ despite a large number of demographic control variables, suggesting a large degree of heterogeneity in the dataset. Notably, Bachmann et al. (2015) testing the determinants of spending in the same survey report very low $R^{2}$ s as well.
} 
expectations. ${ }^{19}$ Interestingly, the effect of inflation volatility becomes insignificant when we distinguish between positive and negative updates. Higher absolute forecast errors in the first interview lead consumers to reduce their inflation expectations. Since consumers generally tend to overestimate inflation during our sample period, a reduction of their forecast after observing a larger error would be consistent.

Table 4: Updating One-Year-Ahead Quantitative Inflation Expectations

\begin{tabular}{l|ccccc}
\hline & $(1)$ & $(2)$ & $(3)$ & $(4)^{1}$ & $(5)^{1}$ \\
\hline$\Delta(\text { Newsprices })_{i t}$ & $0.014^{*}$ & $0.015^{*}$ & $0.015^{*}$ & $0.053^{* *}$ & $0.051^{* *}$ \\
& $(0.008)$ & $(0.008)$ & $(0.008)$ & $(0.025)$ & $(0.025)$ \\
$\sigma_{\pi, t-2}^{2}$ & 0.002 & & & & -0.008 \\
$\sigma_{\pi_{p r o f, t-1}^{e, 1 y r}}^{2}$ & $(0.002)$ & & & & $(0.006)$ \\
$\sigma_{\pi_{\text {cons }, t-2}^{2}}^{e, 1 y r}$ & & $0.073^{* * *}$ & & & $0.116^{* * *}$ \\
$A F E_{i, t-6}$ & & $(0.013)$ & & & $(0.043)$ \\
& & & 0.003 & & -0.006 \\
\hline Observations & & & $(0.002)$ & & $(0.008)$ \\
Demographic Controls & Yes & & & $0.087^{* * *}$ & $0.089^{* * *}$ \\
Pseudo $R^{2}$ & 0.00117 & 0.00156 & 0.00123 & $(0.004)$ & $(0.004)$ \\
Wald test for exogeneity & & & & 4.411 & 6.669 \\
Prob. & & & & 0.0357 & 0.00981 \\
\hline
\end{tabular}

Note: Marginal effects with clustered standard errors in parentheses. ${ }^{* * *},{ }^{* *}$ and ${ }^{*}$ denote significance at the $1 \%, 5 \%$ and $10 \%$ level, respectively. ${ }^{1}$ IV probit estimated with maximum likelihood. $\Delta$ (Newsprices $)_{i t}$ is a dummy variable indicating whether individuals have changed their opinion on news heard over prices with respect to the first interview. $\sigma_{\pi, t-2}^{2}$ denotes the sum of squared changes of inflation over from months t- 2 to t- $8 . \sigma_{\pi_{p r o f, t-1}^{e, 1 y r}}^{2}$ represents the sum of squared changes of inflation expectations of professional forecasters in the Survey of Professional Forecasters (SPF) over the last two quarters. $\sigma_{\pi_{c o n s, t-2}^{e, 1 y r}}^{2}$ denotes the sum of squared changes of mean inflation expectations of consumers in the Michigan Survey from months t-2 to t- 8 . $A F E_{i, t-6}$ stands for the individual absolute forecast error made with the prediction of the first interview $\left|\left(\pi_{t+6}-E_{i, t-6}\left(\pi_{t+6}\right)\right)\right|$, instrumented with the error made with the annualized 6 -months inflation rate between the interviews.

\footnotetext{
${ }^{19}$ This is indeed shown to be the case in Table 3.
} 
Table 5: Updating One-Year-Ahead Qualitative Inflation Expectations

\begin{tabular}{l|ccccc}
\hline & $(1)$ & $(2)$ & $(3)$ & $(4)^{1}$ & $(5)^{1}$ \\
\hline$\Delta(\text { Newsprices })_{i t}$ & 0.002 & 0.002 & 0.002 & -0.006 & 0.004 \\
& $(0.013)$ & $(0.013)$ & $(0.013)$ & $(0.039)$ & $(0.038)$ \\
$\sigma_{\pi, t-2}^{2}$ & 0.008 & & & & 0.002 \\
$\sigma_{\pi_{p r o f, t-1}^{e, 1 y r}}^{2}$ & $(0.007)$ & & & & $(0.019)$ \\
$\sigma_{\pi_{\text {cons }, t-2}^{2,1 y r}}$ & & $0.116^{*}$ & & & 0.218 \\
$A F E_{i, t-6}$ & & $(0.060)$ & & & $(0.147)$ \\
& & & 0.009 & & 0.012 \\
\hline Observations & & & $(0.007)$ & & $(0.022)$ \\
Demographic Controls & 25,349 & 25,349 & 25,349 & 23,802 & 23,802 \\
Pseudo $R^{2}$ & Yes & Yes & Yes & Yes & Yes \\
Wald test for exogeneity & 0.00278 & 0.00303 & 0.00303 & & $0.024^{* * *}$ \\
Prob. & & & & 1.036 & $0.022^{* * *}$ \\
\hline Note: & & & & 0.309 & 0.456 \\
\hline
\end{tabular}

Note: Marginal effects with clustered standard errors in parentheses. ${ }^{* * *},{ }^{* *}$ and ${ }^{*}$ denote significance at the $1 \%, 5 \%$ and $10 \%$ level, respectively. ${ }^{1}$ IV probit estimated with maximum likelihood. $\Delta$ (Newsprices $)_{i t}$ is a dummy variable indicating whether individuals have changed their opinion on news heard over prices with respect to the first interview. $\sigma_{\pi, t-2}^{2}$ denotes the sum of squared changes of inflation over from months t-2 to t- $8 . \sigma_{\pi_{\text {prof }, \text { th }}^{e, 1 y r}}^{2}$ represents the sum of squared changes of inflation expectations of professional forecasters in the Survey of Professional Forecasters (SPF) over the last two quarters. $\sigma_{\pi_{c o n s, t-2}^{e, 1 y r}}^{2}$ denotes the sum of squared changes of mean inflation expectations of consumers in the Michigan Survey from months t-2 to t- 8 . $A F E_{i, t-6}$ stands for the individual absolute forecast error made with the prediction of the first interview $\left|\left(\pi_{t+6}-E_{i, t-6}\left(\pi_{t+6}\right)\right)\right|$, instrumented with the error made with the annualized 6 -months inflation rate between the interviews.

Figure 2: Marginal Effect of the CPI Inflation Variance on Inflation Expectations

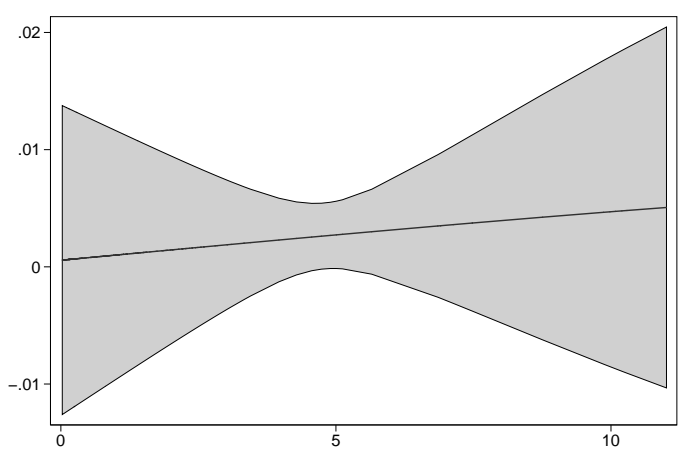

(a) Quantitative Expectations

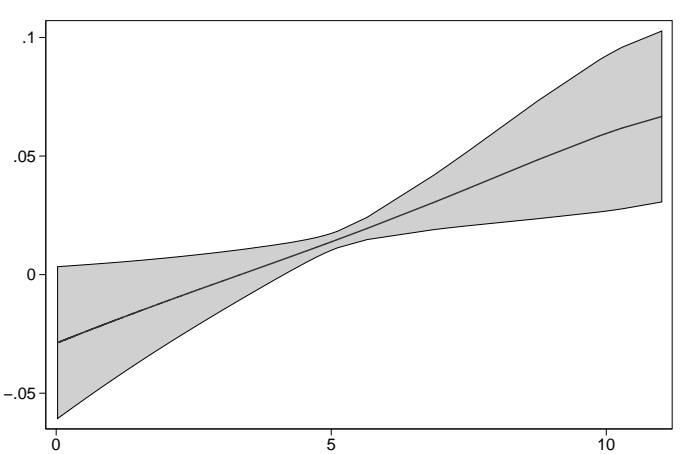

(b) Qualitative Expectations

Notes: The graph shows marginal effects of the CPI inflation variance on the likelihood of an inflation expectations update at rising values of the variance. The y-axis measures the marginal effects which depends on the level of inflation volatility depicted on the x-axis. Shaded areas are $95 \%$ confidence intervals. The left picture shows the marginal effect on updating quantitative short-run inflation expectations, while the right picture shows the effect on an update of qualitative expectations. 
Table 6: Updating One-Year-Ahead Quantitative Inflation Expectations and Non-Linear Volatility Effects

\begin{tabular}{|c|c|c|c|}
\hline & (1) & $(2)$ & (3) \\
\hline$\Delta(\text { Newsprices })_{i t}$ & $\begin{array}{l}0.045^{*} \\
(0.024)\end{array}$ & $\begin{array}{l}0.047^{*} \\
(0.024)\end{array}$ & $\begin{array}{c}0.047^{* *} \\
(0.024)\end{array}$ \\
\hline$\sigma_{\pi, t-2}^{2}$ & $\begin{array}{c}0.001 \\
(0.016)\end{array}$ & & \\
\hline$\left(\sigma_{\pi, t-2}^{2}\right)^{2}$ & $\begin{array}{c}0.001 \\
(0.002)\end{array}$ & & \\
\hline$\sigma_{\pi_{p r o f, t-1}^{e, 1 y r}}^{2}$ & & $0.296^{*}$ & \\
\hline \multirow{2}{*}{$\left(\sigma_{\pi_{p r o f, t-1}^{e, 1 y r}}^{2}\right)^{2}$} & & $\begin{array}{l}(0.179) \\
-0.122\end{array}$ & \\
\hline & & $(0.255)$ & \\
\hline \multirow{2}{*}{$\sigma_{\pi_{\text {cons }, t-2}^{e, 1 y r}}^{2}$} & & & -0.011 \\
\hline & & & $(0.018)$ \\
\hline \multirow{2}{*}{$\left(\sigma_{\pi_{\text {cons }, t-2}^{e, 1 y r}}^{2}\right)^{2}$} & & & 0.002 \\
\hline & & & $(0.002)$ \\
\hline Observations & 24,021 & 24,021 & 24,021 \\
\hline Demographic Controls & Yes & Yes & Yes \\
\hline Pseudo $R^{2}$ & 0.00117 & 0.00157 & 0.00131 \\
\hline
\end{tabular}

Note: Marginal effects with clustered standard errors in parentheses. ${ }^{* * *},{ }^{* *}$ and ${ }^{*}$ denote significance at the $1 \%, 5 \%$ and $10 \%$ level, respectively. $\Delta$ (Newsprices $)_{i t}$ is a dummy variable indicating whether individuals have changed their opinion on news heard over prices with respect to the first interview. $\sigma_{\pi, t-2}^{2}$ denotes the sum of squared changes of inflation over from months t-2 to t- 8 . $\sigma_{\pi_{p r o f, t-1}^{e, 1 y r}}^{2}$ represents the sum of squared changes of inflation expectations of professional forecasters in the Survey of Professional Forecasters (SPF) over the last two quarters. $\sigma_{\pi_{\text {cons }, t-2}^{e, 1 \text { r }}}^{2}$ denotes the sum of squared changes of mean inflation expectations of consumers in the Michigan Survey from months t-2 to t- 8 . 
Table 7: Updating One-Year-Ahead Qualitative Inflation Expectations and Non-Linear Volatility Effects

\begin{tabular}{|c|c|c|c|}
\hline & (1) & $(2)$ & (3) \\
\hline$\Delta(\text { Newsprices })_{i t}$ & $\begin{array}{c}0.011 \\
(0.033)\end{array}$ & $\begin{array}{c}0.008 \\
(0.034)\end{array}$ & $\begin{array}{c}0.0102 \\
(0.033)\end{array}$ \\
\hline$\sigma_{\pi, t-2}^{2}$ & $\begin{array}{c}-0.078^{*} \\
(0.042)\end{array}$ & & \\
\hline$\left(\sigma_{\pi, t-2}^{2}\right)^{2}$ & $\begin{array}{c}0.011^{* * *} \\
(0.004)\end{array}$ & & \\
\hline \multirow{2}{*}{$\sigma_{\pi_{p r o f, t-1}^{e, 1 y r}}^{2}$} & & 0.122 & \\
\hline & & $(0.508)$ & \\
\hline \multirow{2}{*}{$\left(\sigma_{\pi_{p r o f, t-1}^{e, 1 y r}}^{2}\right)^{2}$} & & 0.298 & \\
\hline & & $(0.754)$ & \\
\hline \multirow{2}{*}{$\sigma_{\pi_{c o n s, t-2}^{e, 1 y r}}^{2}$} & & & -0.025 \\
\hline & & & $(0.0347)$ \\
\hline \multirow{2}{*}{$\left(\sigma_{\pi_{c o n s, t-2}^{e, 1 y r}}^{2}\right)^{2}$} & & & 0.006 \\
\hline & & & $(0.004)$ \\
\hline Observations & 25,349 & 25,349 & 25,349 \\
\hline Demographic Controls & Yes & Yes & Yes \\
\hline Pseudo $R^{2}$ & 0.00451 & 0.00307 & 0.00347 \\
\hline
\end{tabular}

Note: Marginal effects with clustered standard errors in parentheses. ${ }^{* * *},{ }^{* *}$ and ${ }^{*}$ denote significance at the $1 \%, 5 \%$ and $10 \%$ level, respectively. $\Delta$ (Newsprices $)_{i t}$ is a dummy variable indicating whether individuals have changed their opinion on news heard over prices with respect to the first interview. $\sigma_{\pi, t-2}^{2}$ denotes the sum of squared changes of inflation over from months t-2 to t- 8 . $\sigma_{\pi_{\text {prof.t-1 }}^{e, 1 y r}}^{2}$ represents the sum of squared changes of inflation expectations of professional forecasters in the Survey of Professional Forecasters (SPF) over the last two quarters. $\sigma_{\pi_{\text {cons }, t-2}^{e, 1 y r}}^{2}$ denotes the sum of squared changes of mean inflation expectations of consumers in the Michigan Survey from months t-2 to t- 8 . 
Table 8: Updating One-Year-Ahead Quantitative Inflation Expectations and News

\begin{tabular}{|c|c|c|c|c|c|c|}
\hline & (1) & $(2)$ & $(3)$ & $(4)$ & $(5)$ & (6) \\
\hline$\sigma_{\pi_{p r o f, t-1}^{e, 1 y r}}^{2}$ & $\begin{array}{c}0.071^{* * *} \\
(0.012)\end{array}$ & $\begin{array}{c}0.073^{* * *} \\
(0.012)\end{array}$ & $\begin{array}{c}0.074^{* * *} \\
(0.018)\end{array}$ & $\begin{array}{c}0.075^{* * *} \\
(0.018)\end{array}$ & $\begin{array}{c}0.073^{* * *} \\
(0.012)\end{array}$ & $\begin{array}{r}0.073^{* * *} \\
(0.012)\end{array}$ \\
\hline$\Delta(\text { Newsheard })_{i t}$ & $\begin{array}{c}0.011^{* *} \\
(0.005)\end{array}$ & & & $\begin{array}{c}0.011 \\
(0.009)\end{array}$ & & \\
\hline$\Delta(\text { Newsprices })_{i t}$ & & $\begin{array}{l}0.015^{*} \\
(0.008)\end{array}$ & & $\begin{array}{c}0.006 \\
(0.012)\end{array}$ & & \\
\hline$\Delta(\text { Volume })_{t-1}$ & & & $\begin{array}{l}-0.000 \\
(0.001)\end{array}$ & $\begin{array}{l}-0.000 \\
(0.001)\end{array}$ & & \\
\hline$\Delta(\text { Newsprices_high })_{i t}$ & & & & & $\begin{array}{c}0.013 \\
(0.008)\end{array}$ & \\
\hline$\Delta\left(\right.$ Newsprices_low $_{i t}$ & & & & & $\begin{array}{c}0.028 \\
(0.018)\end{array}$ & \\
\hline$\Delta(\text { Newsprices_bad })_{i t}$ & & & & & & $\begin{array}{c}0.015 \\
(0.009)\end{array}$ \\
\hline$\Delta(\text { Newsprices_good })_{i t}$ & & & & & & $\begin{array}{l}0.020 \\
(0.015)\end{array}$ \\
\hline Observations & 24,021 & 24,021 & 11,710 & 11,710 & 24,021 & 24,021 \\
\hline Demographic Controls & Yes & Yes & Yes & Yes & Yes & Yes \\
\hline Pseudo $R^{2}$ & 0.00163 & 0.00156 & 0.00209 & 0.00230 & 0.00159 & 0.00158 \\
\hline
\end{tabular}

Note: Marginal effects with clustered standard errors in parentheses. ${ }^{* * *},{ }^{* *}$ and ${ }^{*}$ denote significance at the $1 \%, 5 \%$ and $10 \%$ level, respectively. $\sigma_{\pi_{p r o f, t-1}^{e, 1 y r}}^{2}$ represents the sum of squared changes of inflation expectations of professional forecasters in the Survey of Professional Forecasters (SPF) over the last two quarters. $\Delta$ (Newsheard $)_{i t}$ is a dummy variable indicating whether individuals have changed their opinion on news heard in general with respect to the first interview. $\Delta(\text { Newsprices })_{i t}$ indicates changes in news heard about prices. $\Delta(\text { Volume })_{t-1}$ denotes the change in the volume of media news on inflation within the past six months, starting in the last observed period. $\Delta(\text { Newsprices_high })_{i t}$, $\Delta(\text { Newsprices_low })_{i t}, \Delta(\text { Newsprices_good })_{i t}$ and $\Delta(\text { Newsprices_bad })_{i t}$ denote changes in news heard on rising/falling inflation and prices as well as favorable and unfavorable news. 
Table 9: Updating One-Year-Ahead Qualitative Inflation Expectations and News

\begin{tabular}{|c|c|c|c|c|c|c|}
\hline & (1) & $(2)$ & (3) & $(4)$ & $(5)$ & (6) \\
\hline$\sigma_{\pi_{p r o f, t-1}^{e, 1 y r}}^{2}$ & $\begin{array}{l}0.116^{*} \\
(0.060)\end{array}$ & $\begin{array}{l}0.116^{*} \\
(0.060)\end{array}$ & $\begin{array}{l}0.244^{* * *} \\
(0.072)\end{array}$ & $\begin{array}{c}0.242^{* * *} \\
(0.073)\end{array}$ & $\begin{array}{l}0.116^{*} \\
(0.060)\end{array}$ & $\begin{array}{l}0.115^{*} \\
(0.060)\end{array}$ \\
\hline$\Delta(\text { Newsheard })_{i t}$ & $\begin{array}{c}0.004 \\
(0.005)\end{array}$ & & & $\begin{array}{l}-0.001 \\
(0.007)\end{array}$ & & \\
\hline$\Delta(\text { Newsprices })_{i t}$ & & $\begin{array}{c}0.002 \\
(0.013)\end{array}$ & & $\begin{array}{l}-0.013 \\
(0.014)\end{array}$ & & \\
\hline$\Delta\left(\right.$ Volume $_{t-1}$ & & & $\begin{array}{l}-0.001 \\
(0.001)\end{array}$ & $\begin{array}{l}-0.001 \\
(0.001)\end{array}$ & & \\
\hline$\Delta(\text { Newsprices_high })_{i t}$ & & & & & $\begin{array}{l}-0.002 \\
(0.014)\end{array}$ & \\
\hline$\Delta(\text { Newsprices_low })_{i t}$ & & & & & $\begin{array}{c}0.021 \\
(0.027)\end{array}$ & \\
\hline$\Delta(\text { Newsprices_bad })_{i t}$ & & & & & & $\begin{array}{l}-0.006 \\
(0.013)\end{array}$ \\
\hline$\Delta(\text { Newsprices_good })_{i t}$ & & & & & & $\begin{array}{c}0.032 \\
(0.020)\end{array}$ \\
\hline Observations & 25,349 & 25,349 & 12,578 & 12,578 & 25,349 & 25,349 \\
\hline Demographic Controls & Yes & Yes & Yes & Yes & Yes & Yes \\
\hline Pseudo $R^{2}$ & 0.00305 & 0.00303 & 0.00698 & 0.00705 & 0.00306 & 0.00311 \\
\hline
\end{tabular}

Note: Marginal effects with clustered standard errors in parentheses. ${ }^{* * *},{ }^{* *}$ and ${ }^{*}$ denote significance at the $1 \%, 5 \%$ and $10 \%$ level, respectively. $\sigma_{\pi_{p r o f, t-1}^{e, 1 y r}}^{2}$ represents the sum of squared changes of inflation expectations of professional forecasters in the Survey of Professional Forecasters (SPF) over the last two quarters. $\Delta$ (Newsheard $)_{i t}$ is a dummy variable indicating whether individuals have changed their opinion on news heard in general with respect to the first interview. $\Delta(\text { Newsprices })_{i t}$ indicates changes in news heard about prices. $\Delta(\text { Volume })_{t-1}$ denotes the change in the volume of media news on inflation within the past six months, starting in the last observed period. $\Delta(\text { Newsprices_high })_{i t}$, $\Delta(\text { Newsprices_low })_{i t}, \Delta(\text { Newsprices_good })_{i t}$ and $\Delta(\text { Newsprices_bad })_{i t}$ denote changes in news heard on rising/falling inflation and prices as well as favorable and unfavorable news. 
Table 10: Updating One-Year-Ahead Quantitative Inflation Expectations and NonLinearities between Positive and Negative Updates

\begin{tabular}{|c|c|c|c|c|c|}
\hline $\begin{array}{l}\text { Likelihood of an increase } \\
\text { in inflation expectations }\end{array}$ & (1) & $(2)$ & (3) & $(4)^{1}$ & $(5)^{1}$ \\
\hline$\Delta\left(\right.$ Newsprices $_{i t}$ & \multirow{6}{*}{$\begin{array}{c}0.064^{* * *} \\
(0.018) \\
-0.003 \\
(0.002)\end{array}$} & \multirow[t]{2}{*}{$\begin{array}{c}0.064^{* * *} \\
(0.017)\end{array}$} & \multirow[t]{4}{*}{$\begin{array}{c}0.063^{* * *} \\
(0.018)\end{array}$} & \multirow[t]{5}{*}{$\begin{array}{c}0.154^{* * *} \\
(0.044)\end{array}$} & $\begin{array}{c}0.152^{* * *} \\
(0.043)\end{array}$ \\
\hline$\sigma_{\pi, t-2}^{2}$ & & & & & $\begin{array}{c}0.009 \\
(0.011)\end{array}$ \\
\hline$\sigma_{\pi_{\text {my }}^{e, 1 y r}}^{2}$ & & -0.072 & & & -0.080 \\
\hline & & $(0.070)$ & & & $(0.185)$ \\
\hline$\sigma_{\pi^{e, 1 y r}}^{2}$ & & & \multirow{2}{*}{$\begin{array}{l}-0.007 \\
(0.005)\end{array}$} & & -0.008 \\
\hline$A F E_{i, t-6}$ & & & & $\begin{array}{c}-0.048^{* * *} \\
(0.008) \\
\end{array}$ & $\begin{array}{c}(0.015) \\
-0.048^{* * *} \\
(0.008)\end{array}$ \\
\hline Observations & \multirow{5}{*}{$\begin{array}{c}17,675 \\
\text { Yes } \\
0.00307\end{array}$} & 17,675 & \multirow{5}{*}{$\begin{array}{c}17,675 \\
\text { Yes } \\
0.00344\end{array}$} & 17,499 & 17,499 \\
\hline Demographic Controls & & Yes & & Yes & Yes \\
\hline Pseudo $R^{2}$ & & 0.00330 & & & \\
\hline Wald test for exogeneity & & & & 0.838 & 0.846 \\
\hline Prob. & & & & 0.360 & 0.358 \\
\hline
\end{tabular}

Note: Marginal effects for the likelihood of an increase in quantitative inflation expectations with clustered standard errors in parentheses. ${ }^{* * *},{ }^{* *}$ and ${ }^{*}$ denote significance at the $1 \%, 5 \%$ and $10 \%$ level, respectively. ${ }^{1}$ IV probit estimated with maximum likelihood. $\Delta$ (Newsprices) $)_{i t}$ is a dummy variable indicating whether individuals have changed their opinion on news heard over prices with respect to the first interview. $\sigma_{\pi, t-2}^{2}$ denotes the sum of squared changes of inflation over from months t-2 to t- $8 . \sigma_{\pi_{p r o f, t-1}^{e, 1 y r}}^{2}$ represents the sum of squared changes of inflation expectations of professional forecasters in the Survey of Professional Forecasters (SPF) over the last two quarters. $\sigma_{\pi_{c o n s, t-2}^{e, 1 y r}}^{2}$ denotes the sum of squared changes of mean inflation expectations of consumers in the Michigan Survey from months t-2 to t-8. $A F E_{i, t-6}$ stands for the individual absolute forecast error made with the prediction of the first interview $\left|\left(\pi_{t+6}-E_{i, t-6}\left(\pi_{t+6}\right)\right)\right|$, instrumented with the error made with the annualized 6 -months inflation rate between the interviews. 


\subsection{Explaining Individual Forecast Errors}

After analyzing the factors that may trigger an updating of short-run and long-run expectations in the previous section, we next evaluate forecast errors calculated from oneyear-ahead quantitative inflation expectations for those individuals.

Figure 3 presents a Boxplot of individual forecast errors. Over the estimation period starting in $1987 \mathrm{~m} 10$, errors are about zero on average, with the exception of largely negative forecast errors at the start of the financial crisis in 2008, when actual and expected inflation moved temporarily in opposite directions. ${ }^{20}$ Furthermore, individual forecast errors have slightly more mass on the negative side. This suggests that more individuals overestimated, rather than underestimated, inflation during the sample period.

Figure 3: Boxplot of Individual Forecast Errors

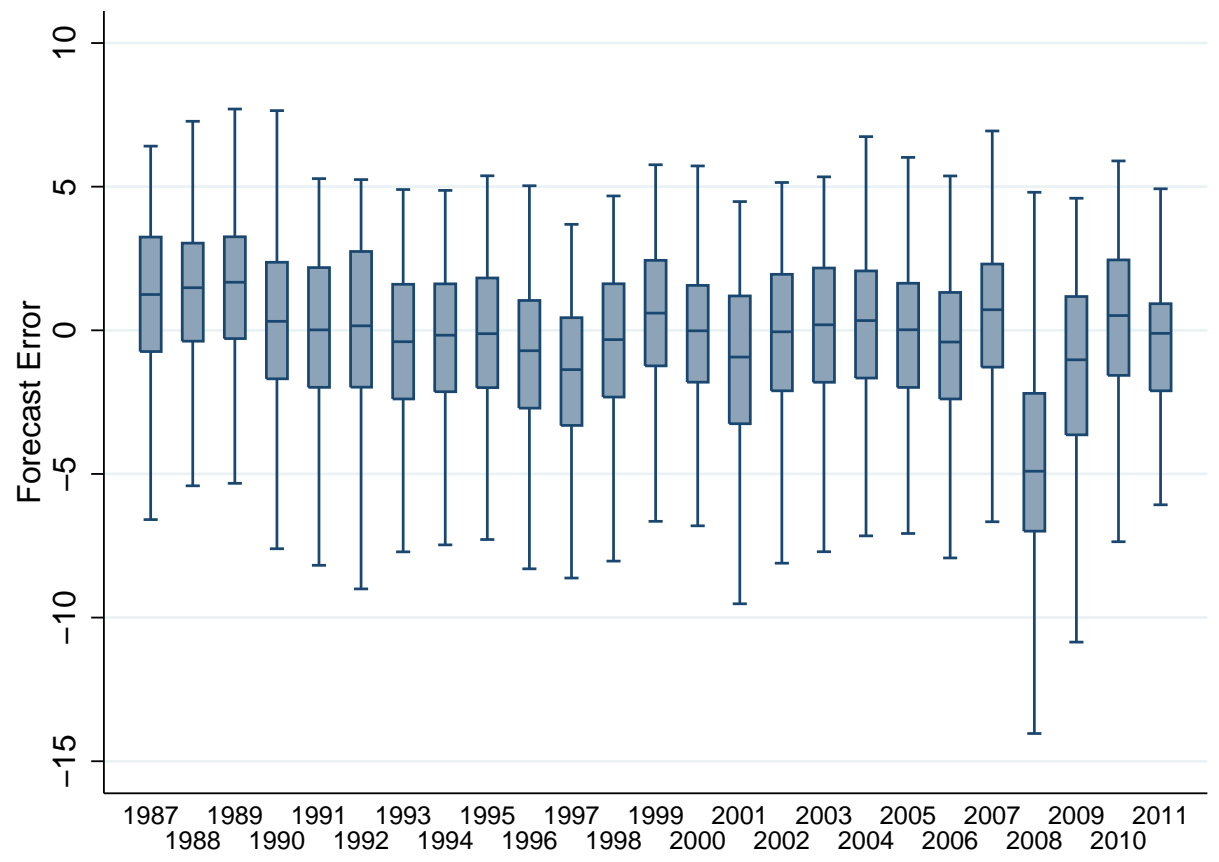

The results in the previous sections give evidence of information frictions affecting individuals' attentiveness towards inflation in line with the theoretical hypotheses H1-H3. However, the question remains whether more attentiveness towards inflation, resulting in a higher probability of updating inflation forecasts, also coincides with a higher forecast

\footnotetext{
${ }^{20}$ Forecast errors since $1987 \mathrm{~m} 10$ have a mean of -0.572 and standard deviation of 3.418 , with a minimum of -19.254 and a maximum of 7.703. Hence, on statistical grounds, given standard levels of confidence, this calculated mean is not different from zero.
} 
accuracy. In short: Does updating improve the forecast accuracy? Therefore, we next analyze how absolute forecast errors regarding inflation change when short-run inflation expectations were updated between interviews as opposed to the case when no update occurred.

Table 11: Individual Changes in Absolute Forecast Errors Conditional on Updating

\begin{tabular}{l|cccccc}
\hline & Mean & Median & SD & Obs & $\begin{array}{c}\text { T-test for } \\
\text { mean }=0\end{array}$ & $\begin{array}{c}\text { T-test for } \\
\text { equal. of means }\end{array}$ \\
\hline All & -0.61 & -0.11 & 4.14 & 24,385 & - & - \\
\hline short-run quant. updated & -0.85 & -0.38 & 4.78 & 17,900 & $-23.67^{* * *}$ & $15.13^{* * *}$ \\
short-run quant. not updated & 0.06 & 0.04 & 0.96 & 6,485 & $4.933^{* * *}$ & - \\
\hline short-run qual. updated & -0.93 & -0.37 & 4.33 & 9,176 & $-20.68^{* * *}$ & $9.66^{* * *}$ \\
short-run qual. not updated & -0.41 & -0.03 & 4.02 & 15,209 & $-12.48^{* * *}$ & - \\
\hline
\end{tabular}

Note: Summary statistics for the truncated sample from 1987m10-2011m11. SD denotes the standard errors and $\mathrm{Obs}$ the number of observations. The t-statistics give the result of a test against the null hypothesis that the change forecast errors is equal to zero and for an equality of means test between the groups, respectively. ${ }^{* *},{ }^{* *}$ and $*$ denote significance at the $1 \%, 5 \%$ and $10 \%$ level.

Table 12: Changes in Absolute Forecast Errors Conditional on Updating and News

\begin{tabular}{l|ccccc}
\hline \multicolumn{1}{c|}{ News Variable } & Mean & SD & Obs & $\begin{array}{c}\text { T-test for } \\
\text { mean }=0\end{array}$ & $\begin{array}{c}\text { T-test for } \\
\text { equal. of means }\end{array}$ \\
\hline No economic news observed & -0.96 & 5.31 & 6,995 & $-15.06^{* * *}$ & $-2.47^{* *}$ \\
Some economic news observed & -0.78 & 4.41 & 10,905 & $-18.36^{* * *}$ & - \\
\hline Observed news on high prices/inflation & -0.02 & 4.33 & 849 & -0.115 & - \\
Observed news on low prices/inflation & -1.15 & 4.89 & 164 & $-3.01^{* * *}$ & - \\
\hline
\end{tabular}

Note: Summary statistics for the truncated sample from $1987 \mathrm{~m} 10-2011 \mathrm{~m} 11$ conditional on the updating of quantitative short-run inflation expectations. $S D$ denotes the standard errors and $O b s$ the number of observations. The t-statistics give the result of a test against the null hypothesis that the change forecast errors is equal to zero and for an equality of means test between the groups, respectively. ${ }^{* * *},{ }^{* *}$ and $*$ denote significance at the $1 \%, 5 \%$ and $10 \%$ level.

Table 11 presents summary statistics for the individual changes in absolute forecast errors between interviews. Including all observations, the statistics show that, on average, absolute forecast errors decrease between interviews. ${ }^{21}$ This suggests that in our sample average quantitative inflation expectations are more accurate in the second interview compared to the first interview. However, when we distinguish between individuals that updated either their quantitative or their qualitative inflation expectations and those that did not update, the summary statistics show that absolute forecast errors decrease

\footnotetext{
${ }^{21}$ This finding is also reported in Anderson et al. (2010) who relate changes in forecast errors between interviews to socio-demographic characteristics.
} 
strongly after an update of inflation expectations. In the case when quantitative inflation expectations have not been updated, the absolute forecast error even increases. All these changes are significant at the $1 \%$ level. Hence, the summary statistics give tentative evidence that, on average, an update of inflation expectations improves the forecast accuracy regarding inflation. ${ }^{22}$

Table 12 complements the observation of Table 11 by additionally looking at the effect of observing news. We see that observing economic news in general is not necessarily beneficial for the inflation forecast accuracy in terms of mean improvements of absolute forecast errors, although there is large heterogeneity in the sample. However, if we look closer at news on inflation, we see that the improvement in terms of higher forecast precision is much lower when news on higher prices are perceived as compared to news on lower prices. Hearing news on lower prices or inflation improves the forecast error by more than 1 percentage point, albeit with a large standard deviation. While the change in forecast errors upon perception of news on high prices is not significantly different from zero, the improvement in forecast accuracy after observing news on low prices or inflation is significant at the $1 \%$ level.

\subsection{Robustness Checks}

In this section, we present several robustness checks for our main results regarding the propensity to update short-run qualitative inflation expectations. First, we check whether our results are affected by the sample period chosen and re-estimate our models for the full sample (1978m1-2011m11). Second, we account for a possible attrition bias with respect to both question and interview attrition using the Heckman correction. Finally, we check whether our results are affected by the magnitude of the adjustment of inflation

\footnotetext{
${ }^{22}$ Although the Michigan survey asks about expectations on prices in general, it is possible that respondents relate their answers to their "personal" or demographic-specific inflation experience. If that were the case, we should evaluate forecast errors with respect to individual, rather than aggregate inflation. While Hobijn and Lagakos (2005) document some heterogeneity in inflation rates across sociodemographic groups in the US, in a different data set Pfajfar and Santoro (2009) report only minor differences in groupspecific inflation rates. Nevertheless, more socioeconomically less advantaged groups seem more likely to forecast their group-specific, rather than aggregate inflation. We leave this issue for further research.
} 
expectations and re-estimate the models for changes larger than 1 or 5 percentage points within six months. ${ }^{23}$

Overall, our conclusions remain unaffected throughout all those variations. When estimating the models for the full sample period (1978m1-2011m11), the effect of inflation volatility variables on the propensity to update expectations gains statistical significance. The effect of news on inflation on the updating of expectations diminishes, which may be due to less media reports in the beginning of our sample period.

When accounting for attrition of the respondents with respect to being selected into the rotating panel and to answering the question on inflation expectations, we find that estimation results change only marginally. ${ }^{24}$ This is not surprising as only $5.7 \%$ of the respondents that were re-interviewed failed to report an updated figure for inflation expectations. In addition, we find only a low support for the selection equation as identified through the insignificance of the Wald-test.

Finally, we control for the minimum size of adjustments in inflation expectations and re-calculate updating shares of quantitative inflation expectations of more than 1 and 5 percentage points, respectively. Calculating and plotting these alternative updating frequencies, we find that the updating shares are substantially lower and reveal a higher time variation, suggesting that larger updates occur much less frequently and look more like the qualitative updating measure (see Tables A.5-A.6 and Figure A.2 in the Appendix). This is as expected, as we demonstrated beforehand that qualitative adjustments in expectations are correlated with a substantial quantitative adjustment. The question hence remains if the selection of big and very big movements in expectation has consequences for our empirical results. Regarding the probability to update quantitative short-run inflation expectations by more than 1 or 5 percentage points, we find that macroeconomic determinants become economically more important, while the news channel becomes less relevant.

\footnotetext{
${ }^{23}$ For reasons of space limitations, we present estimation results for the models including the volatility of professionals' inflation forecast and the change in inflation news heard by the individual, i.e. the specification in Table 4, column 2. Robustness checks for all other models are available upon request.

${ }^{24}$ For the selection equation we add further socioeconomic characteristics, i.e. personal status, regional characteristics, race, number of kids and number of adults in the household.
} 
Table 13: Robustness Checks for the Updating of Short-Run Quantitative Inflation Expectations

\begin{tabular}{l|ccccc}
\hline \multirow{2}{*}{ Model } & $(1)$ & $(2)$ & $(3)$ & $(4)$ & $(5)$ \\
& Baseline & Full Sample & Attrition & $>1 \%$ & $>5 \%$ \\
\hline$\sigma_{\pi_{\text {prof }, \text { et-1 }}^{2}}$ & $0.073^{* * *}$ & $0.045^{* * *}$ & $0.071^{* * *}$ & $0.133^{* * *}$ & $0.081^{* * *}$ \\
$\Delta(\text { Newsprices })_{i t}$ & $(0.013)$ & $(0.008)$ & $(0.016)$ & $(0.045)$ & $(0.031)$ \\
& $0.015^{*}$ & 0.011 & $0.015^{*}$ & 0.004 & -0.008 \\
Observations & $(0.008)$ & $(0.007)$ & $(0.009)$ & $(0.009)$ & $(0.006)$ \\
Demographic Controls & & & & & \\
Pseudo $R^{2}$ & 24,021 & 39,374 & 25,323 & 24,021 & 24,021 \\
$\rho$ & Yes & Yes & Yes & Yes & Yes \\
Wald-Test p-value & 0.00156 & 0.00234 & - & 0.00762 & 0.0229 \\
\hline
\end{tabular}

Note: Marginal effects for the probability of an update of short-run quantitative inflation expectations, with clustered standard errors in parentheses. ${ }^{* * *}, * *$ and $*$ denote significance at the $1 \%$, $5 \%$ and $10 \%$ level, respectively. The Baseline model corresponds to the model in Table 4, column 2. $\sigma_{\pi_{p r o f, t-1}^{e, 1 y r}}^{2}$ represents the sum of squared changes of inflation expectations of professional forecasters in the Survey of Professional Forecasters (SPF) over the last two quarters. $\Delta$ (Newsprices) $)_{i t}$ is a dummy variable indicating whether individuals have changed their opinion on news heard over prices with respect to the first interview.

Table 14: Robustness of the Effect of Absolute Forecast Errors on the Updating of ShortRun Quantitative Inflation Expectations

\begin{tabular}{l|ccc}
\hline & $\begin{array}{c}(1) \\
\text { No instrument }\end{array}$ & $\begin{array}{c}(2) \\
\text { IV Probit } \\
\text { Two-Step }\end{array}$ & $\begin{array}{c}(3) \\
\text { IV Probit } \\
\text { ML Estimator }\end{array}$ \\
\hline$\Delta(\text { Newsprices })_{i t}$ & $0.017^{* *}$ & $0.053^{*}$ & $0.053^{* *}$ \\
& $(0.008)$ & $(0.029)$ & $(0.025)$ \\
$A F E_{i, t-6}$ & $0.026^{* * *}$ & $0.087^{* * *}$ & $0.087^{* * *}$ \\
& $(0.002)$ & $(0.004)$ & $(0.004)$ \\
\hline Observations & 23,802 & 23,802 & 23,802 \\
Demographic Controls & Yes & Yes & Yes \\
Pseudo $R^{2}$ & 0.0239 & - & - \\
Wald test for exogeneity & - & 31.11 & 4.411 \\
Prob. & - & 0.000 & 0.0357 \\
\hline
\end{tabular}

Note: Marginal effects for the probability of an update of short-run quantitative inflation expectations, with clustered standard errors in parentheses. ${ }^{* * *},{ }^{* *}$ and ${ }^{*}$ denote significance at the $1 \%, 5 \%$ and $10 \%$ level, respectively. $\Delta$ (Newsprices $)_{i t}$ is a dummy variable indicating whether individuals have changed their opinion on news heard over prices with respect to the first interview. $A F E_{i, t-6}$ measures the individual absolute forecast error regarding inflation made in the first interview. 
The results presented in Table 14 additionally evaluate the robustness of the impact from the absolute forecast error made at the first interview on the likelihood of an expectation update at the second interview (H3) on the instrumental approach. The first column shows the result without any instrumentation, the second column gives the estimate with a two-step IV probit regression, and the final column gives the estimate with maximum likelihood IV probit also shown in Table 8. The results suggest that the significance of the effect does not depend on the instrumental variable approach, but the size of the coefficient increases considerably when we use IV probit estimation. At the same time, the Wald test for exogeneity suggests that instrumenting $A F E_{i, t-6}$ may be appropriate.

\section{Conclusion}

Our study contributes to the understanding of the formation of inflation expectations of consumers. Employing the rotating panel structure of the Michigan Survey of Consumers allows us to identify whether individuals adjust their expectations within a period of six months.

This allows us to explore the relevance of determinants derived from imperfect information models that may trigger an updating of inflation expectations and their impact on the forecast accuracy. Specifically, we find that a rising volatility of professionals' inflation forecasts triggers an updating of consumers' inflation expectations, suggesting that rational inattention or time-varying sticky information may affect the expectation formation process. In addition, individuals' own forecast errors play a role. Perceived news on inflation induce adjustments in quantitative short-run consumers' inflation expectations but has no effect on qualitative and long-run expectations. With regard to the effect of imperfect information on forecast accuracy, we find that an update of short-run inflation expectations reduces the forecast error by up to $1 \%$.

Overall, our results suggest that the updating of consumers' inflation expectations may be partly predicted with theories of imperfect information. However, while we provide evidence in favor of information rigidities, the low explanatory power of the regressions clearly reveals that more has to be done. One aspect might be that while volatility 
increases attention and thus raises the probability of updating expectations, volatility, at the same time, reduces the forecastability of the underlying series. This effect could work in the opposite direction and thus reduce the probability of adjusting expectations. 


\section{References}

Altissimo, F., B. Mojon, and P. Zaffaroni (2007). Fast micro und slow macro: can aggregation explain the persistence of inflation? ECB Working Paper 729.

An, Z., X. S. Sheng, and J. Wallen (2016). Inattention: Measurement, Determinants, and Policy Implications. Technical report, mimeo.

Anderson, R. D., R. Becker, and D. R. Osborn (2010). Heterogeneity in Consumers' Learning about Inflation. Newcastle Discussion Papers in Economics 2.

Andrade, P. and H. Le Bihan (2013). Inattentive professional forecasters. Journal of Monetary Economics 60(8), 967-982.

Bachmann, R., T. O. Berg, and E. R. Sims (2015). Inlation expectations and readiness to spend: Cross-sectional evidence. American Economic Journal: Economic Policy 7 , $1-35$.

Ball, L., N. Gregory Mankiw, and R. Reis (2005). Monetary policy for inattentive economies. Journal of Monetary Economics 52(4), 703-725.

Blanchflower, D. G. and R. Kelly (2008). Macroeconomic literacy, numeracy and the implications for monetary policy. Working Paper Bank of England.

Branch, W. A. (2007). Sticky information and model uncertainty in survey data on inflation expectations. Journal of Economic Dynamics and Control 31(1), 245-276.

Carroll, C. D. (2003). Macroeconomic expectations of households and professional forecasters. Quarterly Journal of Economics 118(1), 269-298.

Carvalho, C. and F. Nechio (2014). Do people understand monetary policy? Journal of Monetary Economics 66, 108-123.

Coibion, O. and Y. Gorodnichenko (2012). What Can Survey Forecasts Tell Us About Information Rigidities? Journal of Political Economy 120(1), 116-159. 
Coibion, O. and Y. Gorodnichenko (2015). Information rigidity and the expectation formation process: A simple framework and new facts. American Economic Review 105(8), $2644-78$.

Döpke, J., J. Dovern, U. Fritsche, and J. Slacalek (2008a). The dynamics of european inflation expectations. The B.E. Journal of Macroeconomics (Topics) 8(1), Article 12.

Döpke, J., J. Dovern, U. Fritsche, and J. Slacalek (2008b). Sticky expectations phillips curves: European evidence. Journal of Money, Credit, and Banking 40(7), 1513-1520.

Dovern, J., U. Fritsche, L. Prakash, and N. Tamirisa (2015). Information rigidities: Comparing average and individual forecasts for a large international panel. International Journal of Forecasting 31(1), 144-154.

Dräger, L. (2016). Recursive inattentiveness with heterogeneous expectations. Macroeconomic Dynamics 20(4), 1073-1100.

Dräger, L. and M. J. Lamla (2012). Updating inflation expectations: Evidence from micro-data. Economics Letters 117, 807-810.

Dräger, L., M. J. Lamla, and D. Pfajfar (2016). Are survey expectations theory-consistent? The role of central bank communication and news. European Economic Review 85(C), $84-111$.

Evans, G. and Honkapohja (2001). Learning and Expectations in Macroeconomics. Princeton, New Jersey: Princeton University Press.

Hobijn, B. and D. Lagakos (2005). Inflation inequality in the United States. Review of Income and Wealth 51(4), 581-606.

Lamla, M. J. and S. Sarferaz (2012). Updating Inflation Expectations. KOF Swiss Economic Institute Working Paper 301.

Maćkowiak, B. and M. Wiederholt (2009). Optimal sticky prices under rational inattention. American Economic Review 99(3), 769-803. 
Malmendier, U. and S. Nagel (2016). Learning from inflation experiences. The Quarterly Journal of Economics 131(1), 53-87.

Mankiw, N. G. and R. Reis (2002). Sticky information versus sticky prices: A proposal to replace the new keynesian phillips curve. The Quarterly Journal of Economics 117(4), $1295-1328$.

Mankiw, N. G. and R. Reis (2011). Imperfect information and aggregate supply. Handbook of Monetary Economics 3A, 182-230.

Mankiw, N. G., R. Reis, and J. Wolfers (2003). Disagreement about inflation expectations. NBER Working Paper 9796.

Matějka, F. and A. McKay (2011). Rational inattention to discrete choices: A new foundation for the multinomial logit model. CERGE-EI Working Paper Series 442.

Pfajfar, D. and E. Santoro (2009). Asymmetries in Inflation Expectations across Sociodemographic Groups. mimeo.

Pfajfar, D. and E. Santoro (2013). News on Inflation and the Epidemiology of Inflation Expectations. Journal of Money, Credit and Banking 45(6), 1045-1067.

Reis, R. (2006). Inattentive consumers. Journal of Monetary Economics 53(8), 17611800.

Sims, C. A. (2003). Implications of rational inattention. Journal of Monetary Economics $50(3)$, 665-690.

Souleles, N. S. (2004). Expectations, heterogenous forecast errors, and consumption: Micro evidence from the michigan consumer sentiment surveys. Journal of Money, Credit, and Banking 36(1), 40-72.

Wiederholt, M. (2010). Rational Inattention. In The New Palgrave Dictionary of Economics (Online Edition ed.).

Woodford, M. (2001). Imperfect common knowledge and the effects of monetary policy. NBER Working Paper 8673. 


\section{Appendix}

\subsection{Derivation of the optimal degree of attention $\kappa^{*}$}

The problem of optimal inattention can be stated as follows:

$$
\min _{\sigma_{\Delta \mid s_{i}}^{2}, \kappa \geq 0} E_{\Delta, s_{i}}\left[\left(\pi_{i}^{e}-\pi^{e, *}\right)^{2}\right]+\mu(N) \kappa
$$

subject to equations (1) and (2), $s_{i}=\Delta+\varepsilon_{i}$ and the information constraint

$$
\frac{1}{2} \log _{2}\left(2 \pi e \sigma_{\Delta}^{2}\right)-\frac{1}{2} \log _{2}\left(2 \pi e \sigma_{\Delta \mid s_{i}}^{2}\right) \leq \kappa
$$

Agents minimize (A.1) over the joint distribution of the true inflation state and the signal, where the joint distribution is chosen to be Gaussian due to the assumption of Gaussian states. Using the law of iterated expectations and because the conditional variance of a Gaussian random variable is constant, the objective function can be written in terms of the conditional variance of inflation:

$$
\begin{array}{r}
\min _{\sigma_{\Delta \mid s_{i}}^{2}, \kappa \geq 0} E_{\Delta, s_{i}}\left[\left(E_{\Delta}\left[\pi^{e, *} \mid s_{i}\right]-\pi^{e, *}\right)^{2}\right]+\mu(N) \kappa \\
=\min _{\sigma_{\Delta \mid s_{i}}^{2}, \kappa \geq 0} E_{s_{i}}\left[\operatorname{Var}\left(\pi^{e, *} \mid s_{i}\right)\right]+\mu(N) \kappa \\
=\min _{\sigma_{\Delta \mid s_{i}}^{2}, \kappa \geq 0} \operatorname{Var}\left(\pi^{e, *} \mid s_{i}\right)+\mu(N) \kappa \\
=\min _{\sigma_{\Delta \mid s_{i}}^{2}, \kappa \geq 0} \theta^{2} \sigma_{\Delta \mid s_{i}}^{2}+\mu(N) \kappa
\end{array}
$$

We thus get the following Lagrangian and corresponding first-order conditions:

$$
\begin{gathered}
\mathcal{L}=\theta^{2} \sigma_{\Delta \mid s_{i}}^{2}+\mu(N) \kappa-\lambda\left[\frac{1}{2} \frac{\ln \sigma_{\Delta}^{2}}{\ln 2}-\frac{1}{2} \frac{\ln \sigma_{\Delta \mid s_{i}}^{2}}{\ln 2}-\kappa\right] \\
\frac{\partial \mathcal{L}}{\partial \sigma_{\Delta \mid s_{i}}^{2}}=\theta^{2}+\frac{1}{2} \lambda \frac{1}{\ln 2} \frac{1}{\sigma_{\Delta \mid s_{i}}^{2}} \stackrel{!}{=} 0 \\
\frac{\partial \mathcal{L}}{\partial \kappa}=\mu(N)+\lambda \stackrel{!}{=} 0 \Rightarrow \lambda=-\mu(N)
\end{gathered}
$$


Using (A.6) in (A.5) then gives the following expression for the conditional variance of inflation $\sigma_{\Delta \mid s_{i}}^{2}$ :

$$
\sigma_{\Delta \mid s_{i}}^{2}=\frac{\mu(N)}{2 \ln (2) \theta^{2}}
$$

Finally, substituting for $\sigma_{\Delta \mid s_{i}}^{2}$ from (A.7) in the information constraint in (A.2) gives an expression for optimal attention towards inflation:

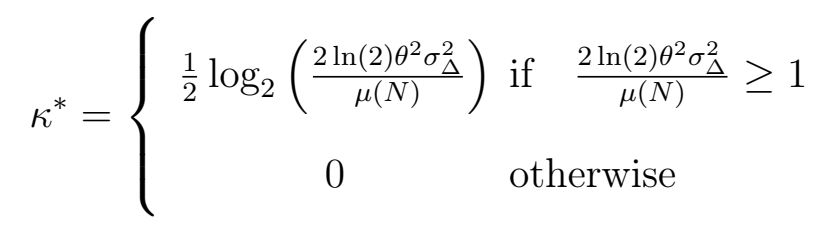

where the fraction $\left(2 \ln (2) \theta^{2} \sigma_{\Delta}^{2}\right) / \mu(N)$ gives the marginal benefit of paying attention to inflation. 


\subsection{News Observed by Consumers}

Figure A.1: Shares of Consumers Reporting News Heard

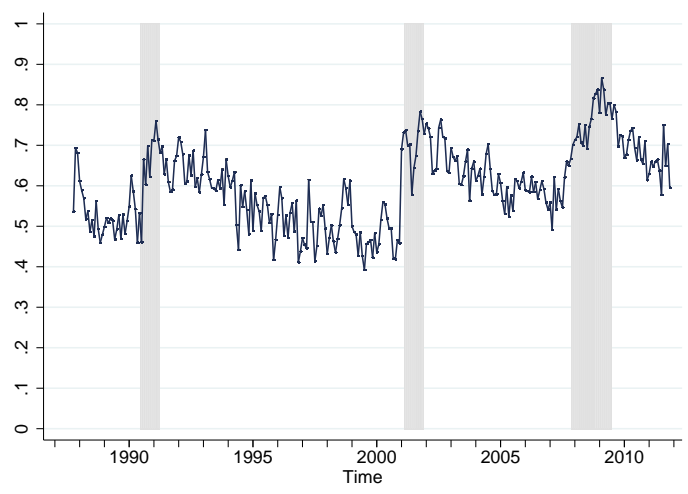

(a) News on Business Conditions in General

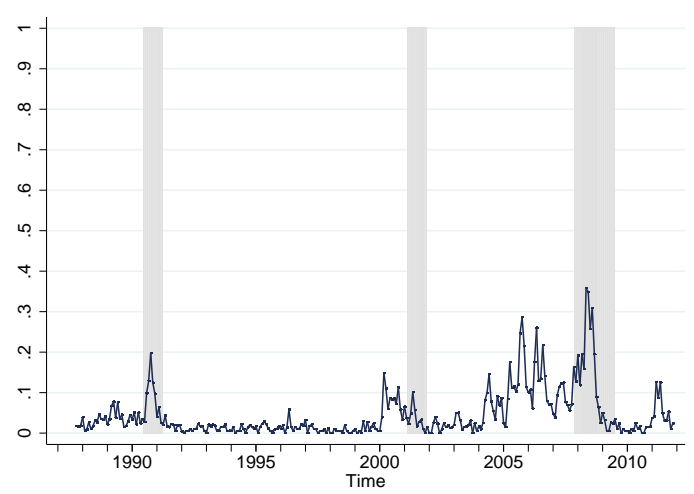

(c) News on Higher Prices

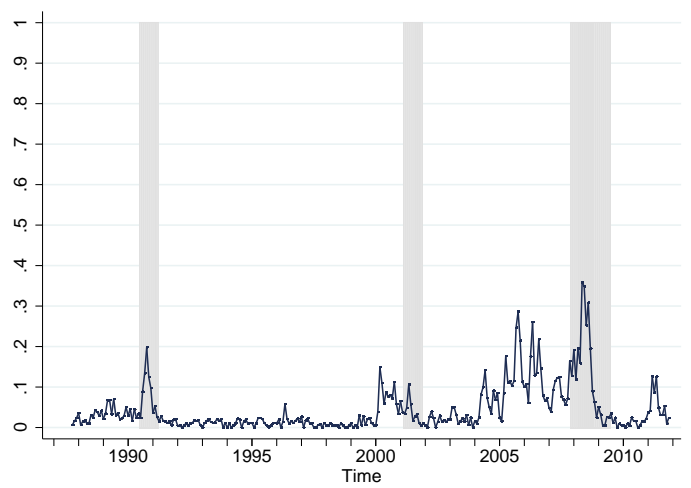

(e) Bad News on Price Changes

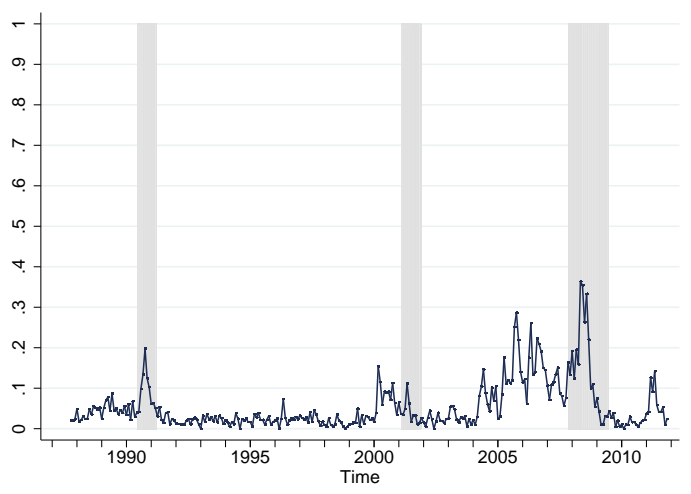

(b) News on Price Changes

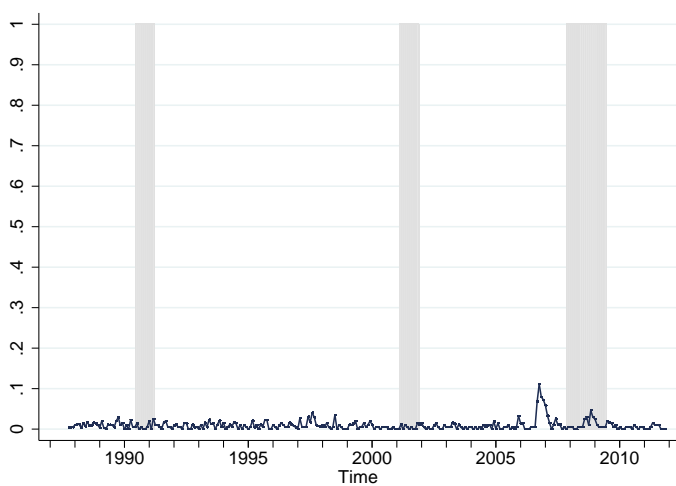

(d) News on Lower Prices

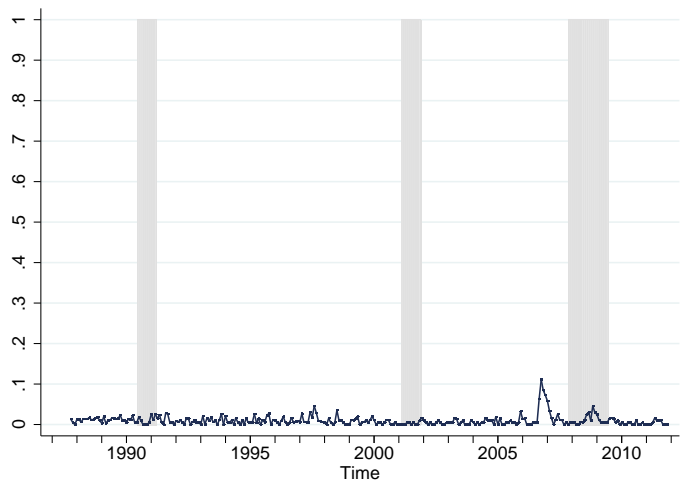

(f) Good News on Price Changes

Notes: The graphs show the share of individual consumers that observed specific news in each monthly cross-section. Shaded areas are recession phases as identified by the NBER. 


\subsection{Updating of Long-Run Inflation Expectations}

Table A.1: Updating Five-to-Ten-Years-Ahead Quantitative Inflation Expectations

\begin{tabular}{|c|c|c|c|c|c|}
\hline & (1) & $(2)$ & $(3)$ & $(4)^{1}$ & $(5)^{1}$ \\
\hline$\Delta(\text { Newsprices })_{i t}$ & -0.003 & $\begin{array}{l}-0.003 \\
(0.008)\end{array}$ & $\begin{array}{l}-0.004 \\
(0.008)\end{array}$ & $\begin{array}{l}-0.009 \\
(0.02)\end{array}$ & $\begin{array}{l}-0.007 \\
(0.024)\end{array}$ \\
\hline$\sigma_{\pi, t-2}^{2}$ & $\begin{array}{c}0.002 \\
(0.003)\end{array}$ & & & & $\begin{array}{l}-0.000 \\
(0.007)\end{array}$ \\
\hline$\sigma_{\pi_{r n-5-10 y r}^{e, ~}}^{2}$ & & 0.028 & & & -0.025 \\
\hline & & $(0.141)$ & & & $(0.298)$ \\
\hline$\sigma_{\pi^{e, 5-10 y r}}^{2}$ & & & $0.007^{* * *}$ & & $0.018^{* * *}$ \\
\hline$A F E_{i, t-6}$ & & & $(0.002)$ & $\begin{array}{c}0.033^{* * *} \\
(0.004)\end{array}$ & $\begin{array}{c}(0.006) \\
0.035^{* * *} \\
(0.006)\end{array}$ \\
\hline Observations & 19,225 & 17,516 & 18,993 & 18,487 & 16,802 \\
\hline Demographic Controls & Yes & Yes & Yes & Yes & Yes \\
\hline Pseudo $R^{2}$ & 0.00507 & 0.00507 & 0.00550 & & \\
\hline Wald test for exogeneity & & & & 0.350 & 0.335 \\
\hline Prob. & & & & 0.554 & 0.563 \\
\hline
\end{tabular}

Note: Marginal effects with clustered standard errors in parentheses. ${ }^{* * *},{ }^{* *}$ and ${ }^{*}$ denote significance at the $1 \%, 5 \%$ and $10 \%$ level, respectively. ${ }^{1} \mathrm{IV}$ probit estimated with maximum likelihood. $\Delta$ (Newsprices $)_{i t}$ is a dummy variable indicating whether individuals have changed their opinion on news heard over prices with respect to the first interview. $\sigma_{\pi, t-1}^{2}$ denotes the sum of squared changes of inflation over the months t-2 to t- $8 . \sigma_{\pi_{p r o f, t-1}^{e, 5-10 y r}}^{2}$ represents the sum of squared changes of long-run inflation expectations of professional forecasters in the Survey of Professional Forecasters (SPF) over the last two quarters. $\sigma_{\pi_{c, 5-10 y r}^{2}}^{2}$ denotes the sum of squared changes of mean long-run inflation expectations of consumers in the Michigan Survey over the months t-2 to t- 8 . $A F E_{i, t-6}$ stands for the individual absolute forecast error made with the prediction of the first interview $\left|\left(\pi_{t+6}-E_{i, t-6}\left(\pi_{t+6}\right)\right)\right|$, instrumented with the error made with the annualized 6 -months inflation rate between the interviews. 
Table A.2: Updating Five-to-Ten-Years-Ahead Qualitative Inflation Expectations

\begin{tabular}{|c|c|c|c|c|c|}
\hline & (1) & (2) & (3) & $(4)^{1}$ & $(5)^{1}$ \\
\hline \multirow[t]{2}{*}{$\Delta(\text { Newsprices })_{i t}$} & -0.006 & -0.013 & -0.009 & -0.038 & -0.040 \\
\hline & $(0.011)$ & $(0.013)$ & $(0.013)$ & $(0.054)$ & $(0.050)$ \\
\hline \multirow[t]{2}{*}{$\sigma_{\pi, t-2}^{2}$} & $0.007 * * *$ & & & & $0.025^{* * *}$ \\
\hline & $(0.001)$ & & & & $(0.006)$ \\
\hline \multirow{2}{*}{$\sigma_{\pi_{p r o f, t-1}^{e, 5-10 y r}}^{2}$} & & -0.039 & & & 0.126 \\
\hline & & $(0.074)$ & & & $(0.277)$ \\
\hline \multirow{2}{*}{$\sigma_{\pi_{c o n s, t-2}^{e, 5-10 y r}}^{2}$} & & & -0.000 & & 0.003 \\
\hline & & & $(0.002)$ & & $(0.009)$ \\
\hline$A F E_{i, t-6}$ & & & & $\begin{array}{c}0.023^{* * *} \\
(0.004)\end{array}$ & $\begin{array}{c}0.021^{* * *} \\
(0.004)\end{array}$ \\
\hline Observations & 20,415 & 18,662 & 20,174 & 19,007 & 17,291 \\
\hline Demographic Controls & Yes & Yes & Yes & Yes & Yes \\
\hline Pseudo $R^{2}$ & 0.0199 & 0.0169 & 0.0176 & & \\
\hline Wald test for exogeneity & & & & 3.367 & 4.577 \\
\hline Prob. & & & & 0.0665 & 0.0324 \\
\hline
\end{tabular}

Note: Marginal effects with clustered standard errors in parentheses. ${ }^{* *},{ }^{* *}$ and ${ }^{*}$ denote significance at the $1 \%, 5 \%$ and $10 \%$ level, respectively. ${ }^{1}$ IV probit estimated with maximum likelihood. $\Delta$ (Newsprices $)_{i t}$ is a dummy variable indicating whether individuals have changed their opinion on news heard over prices with respect to the first interview. $\sigma_{\pi, t-1}^{2}$ denotes the sum of squared changes of inflation over the months t-2 to t- $8 . \sigma_{\pi_{p r o f, t-1}^{e, 5-10 y r}}^{2}$ represents the sum of squared changes of long-run inflation expectations of professional forecasters in the Survey of Professional Forecasters (SPF) over the last two quarters. $\sigma_{\pi_{c o n s, t-2}^{e, 5-10 y r}}^{2}$ denotes the sum of squared changes of mean long-run inflation expectations of consumers in the Michigan Survey over the months t- 2 to t- 8 . $A F E_{i, t-6}$ stands for the individual absolute forecast error made with the prediction of the first interview $\left|\left(\pi_{t+6}-E_{i, t-6}\left(\pi_{t+6}\right)\right)\right|$, instrumented with the error made with the annualized 6-months inflation rate between the interviews. 
Table A.3: Updating Five-to-Ten-Years-Ahead Quantitative Inflation Expectations and News

\begin{tabular}{|c|c|c|c|c|c|c|}
\hline & (1) & $(2)$ & $(3)$ & (4) & $(5)$ & $(6)$ \\
\hline$\sigma_{\pi^{e, 5-10 y r}}^{2}$ & 0.031 & 0.028 & -0.318 & -0.320 & 0.031 & 0.030 \\
\hline & $(0.140)$ & $(0.141)$ & $(0.202)$ & $(0.202)$ & $(0.140)$ & $(0.140)$ \\
\hline$\Delta(\text { Newsheard })_{i t}$ & $\begin{array}{c}0.004 \\
(0.005)\end{array}$ & & & $\begin{array}{l}-0.000 \\
(0.005)\end{array}$ & & \\
\hline$\Delta(\text { Newsprices })_{i t}$ & & $\begin{array}{l}-0.003 \\
(0.008)\end{array}$ & & $\begin{array}{l}-0.007 \\
(0.010)\end{array}$ & & \\
\hline$\Delta(\text { Volume })_{t-1}$ & & & $\begin{array}{l}-0.000 \\
(0.001)\end{array}$ & $\begin{array}{l}-0.000 \\
(0.001)\end{array}$ & & \\
\hline$\Delta(\text { Newsprices_high })_{i t}$ & & & & & $\begin{array}{l}-0.006 \\
(0.010)\end{array}$ & \\
\hline$\Delta(\text { Newsprices_low })_{i t}$ & & & & & $\begin{array}{c}0.011 \\
(0.024)\end{array}$ & \\
\hline$\Delta(\text { Newsprices_bad })_{i t}$ & & & & & & $\begin{array}{l}-0.006 \\
(0.010)\end{array}$ \\
\hline$\Delta(\text { Newsprices_good })_{i t}$ & & & & & & $\begin{array}{c}0.010 \\
(0.024)\end{array}$ \\
\hline Observations & 17,516 & 17,516 & 11,616 & 11,616 & 17,516 & 17,516 \\
\hline Demographic Controls & Yes & Yes & Yes & Yes & Yes & Yes \\
\hline Pseudo $R^{2}$ & 0.00509 & 0.00507 & 0.00425 & 0.00427 & 0.00509 & 0.00509 \\
\hline
\end{tabular}

Note: Marginal effects with clustered standard errors in parentheses. ${ }^{* * *},{ }^{* *}$ and ${ }^{*}$ denote significance at the $1 \%, 5 \%$ and $10 \%$ level, respectively. $\sigma_{\pi_{p r o f, t-1}^{e, 5-10 y r}}^{2}$ represents the sum of squared changes of long-run inflation expectations of professional forecasters in the Survey of Professional Forecasters $(\mathrm{SPF})$ over the last two quarters. $\Delta\left(\right.$ Newsheard $_{i t}$ is a dummy variable indicating whether individuals have changed their opinion on news heard in general with respect to the first

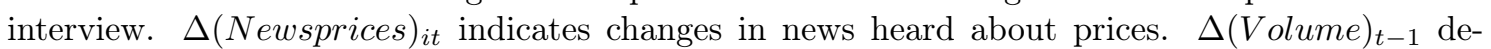
notes the change in the volume of media news on inflation within the past six months, starting in the last observed period. $\Delta(\text { Newsprices_high })_{i t}, \Delta(\text { Newsprices_low })_{i t}, \Delta(\text { Newsprices_good })_{i t}$ and $\Delta$ (Newsprices_bad $)_{i t}$ denote changes in news heard on rising/falling inflation and prices as well as favorable and unfavorable news. 
Table A.4: Updating Five-to-Ten-Years-Ahead Qualitative Inflation Expectations and News

\begin{tabular}{|c|c|c|c|c|c|c|}
\hline & (1) & $(2)$ & (3) & (4) & $(5)$ & $(6)$ \\
\hline$\sigma_{\pi_{p r o f, t-1}^{e, 5-10 y r}}^{2}$ & $\begin{array}{l}-0.037 \\
(0.075)\end{array}$ & $\begin{array}{l}-0.039 \\
(0.074)\end{array}$ & $\begin{array}{c}0.096 \\
(0.197)\end{array}$ & $\begin{array}{c}0.093 \\
(0.198)\end{array}$ & $\begin{array}{l}-0.038 \\
(0.073)\end{array}$ & $\begin{array}{l}-0.038 \\
(0.073)\end{array}$ \\
\hline$\Delta(\text { Newsheard })_{i t}$ & $\begin{array}{c}0.003 \\
(0.003)\end{array}$ & & & $\begin{array}{c}0.001 \\
(0.005)\end{array}$ & & \\
\hline$\Delta(\text { Newsprices })_{i t}$ & & $\begin{array}{l}-0.013 \\
(0.013)\end{array}$ & & $\begin{array}{l}-0.019 \\
(0.014)\end{array}$ & & \\
\hline$\Delta(\text { Volume })_{t-1}$ & & & $\begin{array}{l}-0.001 \\
(0.000)\end{array}$ & $\begin{array}{l}-0.001 \\
(0.000)\end{array}$ & & \\
\hline$\Delta(\text { Newsprices_high })_{i t}$ & & & & & $\begin{array}{l}-0.016 \\
(0.015)\end{array}$ & \\
\hline$\Delta(\text { Newsprices_low })_{i t}$ & & & & & $\begin{array}{l}-0.002 \\
(0.016)\end{array}$ & \\
\hline$\Delta(\text { Newsprices_bad })_{i t}$ & & & & & & $\begin{array}{l}-0.016 \\
(0.015)\end{array}$ \\
\hline$\Delta(\text { Newsprices_good })_{i t}$ & & & & & & $\begin{array}{l}-0.000 \\
(0.015)\end{array}$ \\
\hline Observations & 18,662 & 18,662 & 12,461 & 12,461 & 18,662 & 18,662 \\
\hline Demographic Controls & Yes & Yes & Yes & Yes & Yes & Yes \\
\hline Pseudo $R^{2}$ & 0.0168 & 0.0169 & 0.0168 & 0.0171 & 0.0169 & 0.0169 \\
\hline
\end{tabular}

Note: Marginal effects with clustered standard errors in parentheses. ${ }^{* * *},{ }^{* *}$ and ${ }^{*}$ denote significance at the $1 \%, 5 \%$ and $10 \%$ level, respectively. $\sigma_{\pi_{p r o f, t-1}^{e, 5-10 y r}}^{2}$ represents the sum of squared changes of long-run inflation expectations of professional forecasters in the Survey of Professional Forecasters $(\mathrm{SPF})$ over the last two quarters. $\Delta\left(\right.$ Newsheard $_{i t}$ is a dummy variable indicating whether individuals have changed their opinion on news heard in general with respect to the first

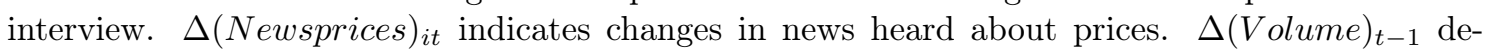
notes the change in the volume of media news on inflation within the past six months, starting in the last observed period. $\Delta(\text { Newsprices_high })_{i t}, \Delta(\text { Newsprices_low })_{i t}, \Delta(\text { Newsprices_good })_{i t}$ and $\Delta$ (Newsprices_bad $)_{i t}$ denote changes in news heard on rising/falling inflation and prices as well as favorable and unfavorable news. 


\subsection{Updating Shares with Quantitative Changes Above 1\% or 5\%}

Table A.5: Summary Statistics of Monthly Updating Shares with Quant. Updates > 1\%

\begin{tabular}{l|ccccc}
\hline \multicolumn{1}{c}{ Variable } & Obs & Mean & SD & Min & Max \\
\hline Short-run expectations, 1 year, update $>1 \%$ & 289 & 0.56 & 0.08 & 0.39 & 0.83 \\
Short-run expectations, 1 year, qualitative answer & 289 & 0.38 & 0.09 & 0.16 & 0.67 \\
Long-run expectations, 5-10 years, update $>1 \%$ & 255 & 0.48 & 0.07 & 0.28 & 0.64 \\
Long-run expectations, 5-10 years, qualitative answer & 255 & 0.17 & 0.05 & 0.03 & 0.34 \\
\hline
\end{tabular}

Notes: Obs denotes the sample size, $S D$ is the standard deviation while Min and Max represent the minimum and maximum values.

Table A.6: Summary Statistics of Monthly Updating Shares with Quant. Updates > 5\%

\begin{tabular}{l|ccccc}
\hline \multicolumn{1}{c}{ Variable } & Obs & Mean & SD & Min & Max \\
\hline Short-run expectations, 1 year, update $>5 \%$ & 289 & 0.15 & 0.07 & 0.03 & 0.55 \\
Short-run expectations, 1 year, qualitative answer & 289 & 0.38 & 0.09 & 0.16 & 0.67 \\
Long-run expectations, 5-10 years, update $>5 \%$ & 255 & 0.11 & 0.05 & 0.00 & 0.26 \\
Long-run expectations, 5-10 years, qualitative answer & 255 & 0.17 & 0.05 & 0.03 & 0.34 \\
\hline
\end{tabular}

Notes: Obs denotes the sample size, $S D$ is the standard deviation while Min and Max represent the minimum and maximum values. 
Figure A.2: Updating Shares for Quantitative Inflation Expectations

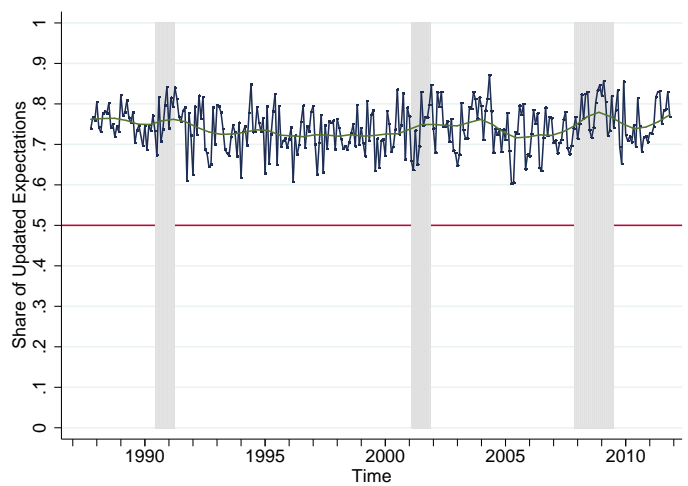

(a) Short-run expectations, 1 year

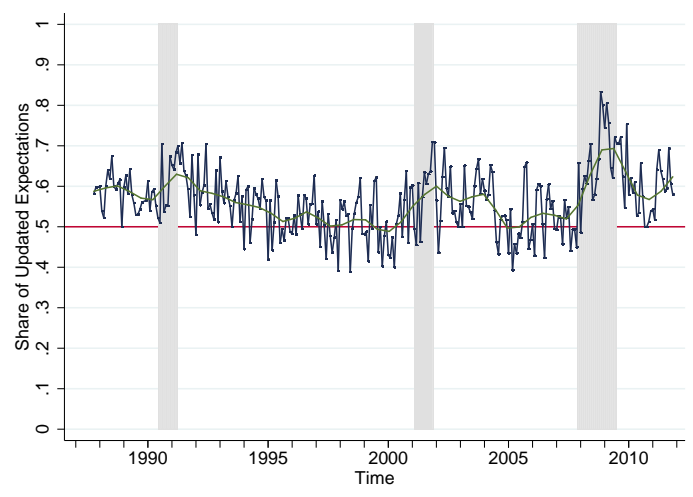

(c) Short-run expectations, update $>1 \%$

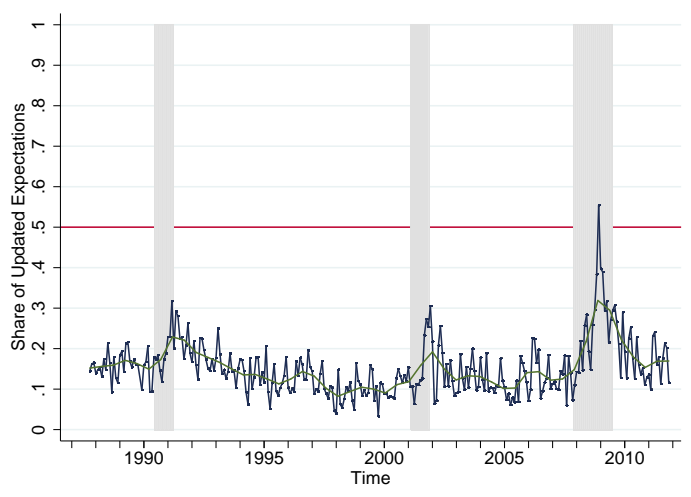

(e) Short-run expectations, update $>5 \%$

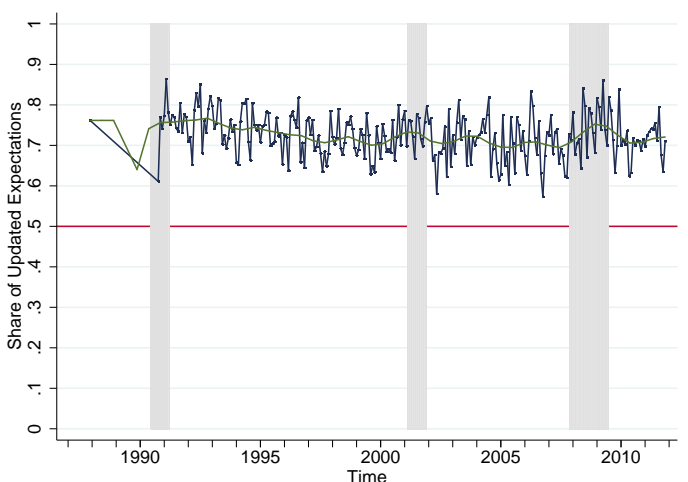

(b) Long-run expectations, 5-10 years

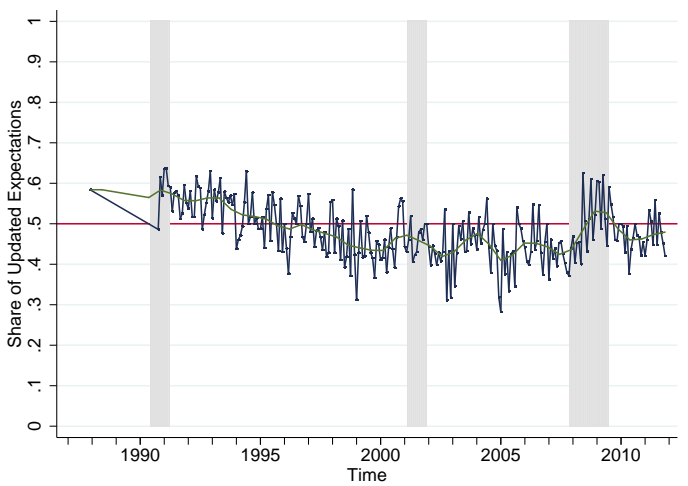

(d) Long-run expectations, update $>1 \%$

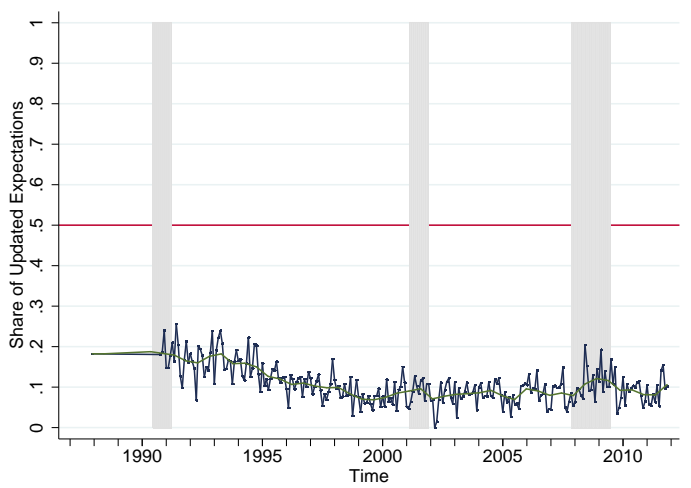

(f) Long-run expectations, update $>5 \%$

Notes: The graphs show the share of individual consumers that change their inflation expectations within six months together with a smoothing polynomial trend. Shaded areas are recession phases as identified by the NBER. The share is calculated by taking all individuals that adjusted their expectations during the last six months and dividing them by the overall number of individuals that have been re-interviewed. 